\title{
Culex quinquefasciatus: status as a threat to island avifauna and options for genetic control
}

\author{
Tim Harvey-Samuel ${ }^{1 \dagger}$, Thomas Ant ${ }^{2 \dagger}$, Jolene Sutton ${ }^{3}$, Chris N. Niebuhr ${ }^{4}$, Samoa Asigau ${ }^{5,6}$, Patricia Parker ${ }^{5,6,7}$, \\ Steven Sinkins ${ }^{2}$ and Luke Alphey ${ }^{*^{*}}$ (D)
}

\begin{abstract}
The avifauna endemic to islands is particularly susceptible to population declines and extinctions resulting from the introduction of non-native pathogens. Three pathogens of concern are the avian malaria parasites, the avian poxviruses, and West Nile virus - each of which can be transmitted by Culex quinquefasciatus, a highly adaptive and invasive mosquito. Culex quinquefasciatus has dramatically expanded its range in recent centuries and is now established throughout much of the tropics and sub-tropics, including on many islands that are remote from mainland landmasses and where this geographic separation historically protected island species from mosquito-borne diseases. The potential for ecological disruption by $C$. quinquefasciatus has been particularly striking in the Hawaiian Islands, where the introduction and transmission of avian malaria and avian poxvirus led to the extinction of several endemic bird species, with many more at risk. With $C x$. quinquefasciatus now present in many insular communities and global trade and tourism increasing links between these areas, both to each other and to mainlands, there is growing concern that patterns of avian decline in Hawai'i may be played out in other insular ecosystems. The implementation of traditional methods for $C$. quinquefasciatus control, including larval source management, is often impractical at large scale and when breeding sites are numerous and difficult to locate - typical issues associated with invasive species removal. One alternative approach would be the utilisation of genetic control methods, several of which have been successfully developed in other mosquitos such as Aedes aegypti and the malaria vector Anopheles gambiae. However, the development of similar tools for $C x$. quinquefasciatus has been comparatively limited. Here we review the threat that $C x$. quinquefasciatus poses as a vector of avian pathogens to island avifauna and discuss specific examples of atrisk bird populations on the islands of Hawai 'i, New Zealand and Galápagos. We also review the major options for the deployment of genetic control tools against $C x$. quinquefasciatus, and discuss the current state of the field with a focus on radiation-based sterilisation, transgenic methods, and transinfections using the bacterial endosymbiont Wolbachia.
\end{abstract}

Keywords: Avian malaria, West nile virus, Avian pox, Genetic biocontrol, Invasive species, Biodiversity, New zealand, Galapagos, Hawaii

\footnotetext{
*Correspondence: luke.alphey@pirbright.ac.uk

${ }^{\dagger}$ Tim Harvey-Samuel and Thomas Ant contributed equally to this work ${ }^{1}$ Arthropod Genetics Group, The Pirbright Institute, Woking GU240NF, Surrey, UK

Full list of author information is available at the end of the article
}

\begin{abstract}
Background
Commonly known as the southern house mosquito, Culex quinquefasciatus is widespread in the tropics and subtropics, where it has been incriminated in the transmission of a diverse array of pathogens important to public health and wildlife (LaPointe 2012). Cx. quinquefasciatus is a member of the Culex pipiens species
\end{abstract}

c) The Author(s) 2021. This article is licensed under a Creative Commons Attribution 4.0 International License, which permits use, sharing, adaptation, distribution and reproduction in any medium or format, as long as you give appropriate credit to the original author(s) and the source, provide a link to the Creative Commons licence, and indicate if changes were made. The images or other third party material in this article are included in the article's Creative Commons licence, unless indicated otherwise in a credit line to the material. If material is not included in the article's Creative Commons licence and your intended use is not permitted by statutory regulation or exceeds the permitted use, you will need to obtain permission directly from the copyright holder. To view a copy of this licence, visit http://creativecommons.org/licenses/by/4.0/. The Creative Commons Public Domain Dedication waiver (http://creativecommons.org/publicdomain/zero/1.0/) applies to the data made available in this article, unless otherwise stated in a credit line to the data. 
complex and is currently found in much of Afro-Eurasia, and in many of the warmer parts of the Americas, where it hybridises with sibling species in areas of overlap. While evidence from microsatellite diversity points to origins in tropical Southeast Asia (Fonseca et al. 2006), the remarkable ecological and host-seeking plasticity of $C x$. quinquefasciatus, combined with a propensity to adapt to human habitation and activity has enabled a vast latitudinal range expansion, aided by a capacity for long distance dispersal by hitchhiking on boats and aircraft (Kilpatrick et al. 2004). Of particular relevance to this review, the range of $C x$. quinquefasciatus now includes islands throughout the Pacific and Indian Oceans, including New Zealand, and volcanic archipelagos such as the Galápagos and Hawaiian Islands-where large distances from continental landmasses historically protected ecosystems from the arrival and establishment of exotic mosquito species and the pathogens they transmit.

Culex quinquefasciatus displays several traits that promote invasiveness. In contrast to 'clean' freshwater mosquitos such as Aedes aegypti or Aedes albopictus, Cx. quinquefasciatus is capable of breeding in 'dirty' eutrophic habitats rich in organic matter, including standing water contaminated with human or animal waste, where it is capable of reaching very high larval densities. Tolerance of these conditions has allowed the exploitation of a variety of polluted human-made habitats such as sewers, ditches, or ponds-leading to close association with humans. This habitat-type flexibility enabled the first large-scale range expansion of $C x$. quinquefasciatus in the seventeenth and eighteenth centuries on expeditionary sailing vessels equipped for longer voyages, where stagnant, polluted water sources and livestock waste were often present (LaPointe 2012). Beyond peridomestic areas, $C x$. quinquefasciatus larvae are found in a range of natural water containers, such as rock pools, puddles and a variety of phytotelmata where organic debris may concentrate (Okiwelu and Noutcha 2012). Furthermore, as a largely opportunistic blood feeder, the proportion of blood meals derived from specific host taxa can vary widely with location and host availability, allowing for a degree of flexibility when arriving in a novel environment. Overall, however, bloodmeal analyses from a variety of study sites indicate that $C x$. quinquefasciatus is primarily ornithophilic (with an average of $\sim 70 \%$ of bloodmeals derived from avian hosts) (Farajollahi et al. 2011), although it can also take a significant portion of feedings from mammalian, amphibian or reptile hosts under some circumstances (Farajollahi et al. 2011; Apperson et al. 2002), with the proportion of human-derived bloodmeals expected to be high in cities in the tropics. Because of its variable host feeding behaviour, Cx. quinquefasciatus occasionally acts as a bridge vector for human transmission of zoonotic pathogens. Perhaps the most significant example of this relates to the sporadic outbreaks of West Nile virus (WNV), a flavivirus that is maintained in an avian enzootic cycle predominantly by Culex mosquitos (Hamer et al. 2009).

Culex quinquefasciatus has been identified as posing a high risk to insular avian communities (LaPointe 2012; Derraik 2006; Anonymous. 2020). In addition to its high invasiveness, it is also a competent vector of a variety of protozoan and viral pathogens of birds including parasites of the genus Plasmodium that cause avian malaria, WNV and viruses belonging to the Avipoxvirus group (see Box 1). Many of these pathogens are relatively well tolerated by avian communities in the continental settings where they are endemic. However, island communities, particularly those which have been isolated from mosquito-borne pathogens for long periods of time, may be more susceptible to severe disease due to a lack of co-evolutionary experience with the pathogen. In these communities, establishment of novel disease transmission-cycles after invasion by an infectious vector, for example, can be a significant driver of biodiversity loss.

Whilst the dangers posed by $C x$. quinquefasciatusvectored diseases to public health have been well summarised (Farajollahi et al. 2011), similar syntheses have not yet been conducted for threats to insular avian communities. Such a synthesis is pertinent given the exacerbating effects of globalised trade and climate change on the movement of $C x$. quinquefasciatus between and within environments housing these vulnerable communities. Here we provide a series of case studies on $C x$. quinquefasciatus and its current and potential effects on the avifauna of three major island groups-Hawai $i$, New Zealand, and Galápagos. Comparison of the distinct situations in these areas will help highlight the commonalties and differences in this species as an invader, identify knowledge gaps and spur further research into areas of its biology that may be useful in its control. It is only through taking a global view that the true threat posed by this species to vulnerable avifauna communities can be accurately gauged. Beyond discussing $C x$. quinquefasciatus as an invasive species, we also assess the options for its area-wide control or removal, focussing on the current state of genetic control technologies. Large-scale implementation of traditional methods for controlling $C x$. quinquefasciatus, including the chemical treatment or physical removal of breeding sites, may be impractical at island-wide scales, where larval habitats may be abundant and difficult to locate and access. In these instances, it may be beneficial to integrate genetic control options that involve the release of modified male and/or female mosquitos with the aim of reducing the vectorial capacity or reproductive potential of the target population. 
This section aims to take stock of what has been achieved so far in relation to $C x$. quinquefasciatus and highlight areas where further research is needed if a genetic/biological solution to the control of this pernicious island invader is to be achieved. Finally, we briefly explore the social issues surrounding the potential deployment of these genetic technologies, acknowledging the justified increasing importance placed on this aspect of fielddeployment programmes. Throughout, we employ case studies that allow exploration of issues particularly pertinent to deployment of these technologies in insular environments.

\section{Box 1: Major avian pathogens transmitted by $C x$. quinquefasciatus. \\ Avian malaria}

Avian malaria is a widespread and common disease of birds caused by more than 40 species of protozoan parasite from the genus Plasmodium. The species Plasmodium relictum in particular has a broad geographical distribution, and has been associated with some dramatic declines of native bird populations (LaPointe et al. 2012). Unlike human malaria, which is solely transmitted by mosquitos in the subfamily Anophelinae, avian malaria can be transmitted by mosquitos belonging to a range of genera from both the Anophelinae and Culicinae subfamilies. Although not all avian Plasmodium species have been linked to a putative vector, members of the $C x$. pipiens complex play a prominent role in transmission (Carlson et al. 2015). Avian malaria parasites undergo a complex life cycle: transmission occurs when an infected mosquito injects a susceptible avian host with sporozoites during blood feeding, which are subsequently carried to reticuloendothelial cells in the skin. After rounds of exoerythrocytic development, merozoite forms are produced and invade red blood cells. Once inside red cells, the merozoites either undergo further asexual reproduction, or can transform into the sexual gametocyte forms - the stage infective to mosquitos (Press 2018). Avian malaria is primarily an infection of the blood and may cause severe anaemia and high mortality, although the acute phase of infection can result in the damage of a variety of other tissues. The acute phase is typically proceeded by strong antibody and cell mediated immunity and a subsequent tolerance to infection. Chronic infections may follow and frequently persist for the lifetime of the bird (LaPointe et al. 2012).

\section{West Nile virus (WNV)}

West Nile virus is a neurotropic arbovirus belonging to the genus Flavivirus. It comprises a positive polarity single-stranded RNA genome which is translated into a single polyprotein upon host cell infection and is subsequently cleaved into the structural and nonstructural proteins responsible for viral replication and assembly (Valiakos et al. 2013). West Nile Virus is maintained in an enzootic mosquito-bird cycle and has been isolated from over 60 mosquito species, with ornithophilic members of the Culex genus often central to transmission. The primary vector species varies by region, with $C x$. quinquefasciatus responsible for a significant portion of WNV transmission in the Americas. West Nile Virus has a broad avian host range: over 300 bird species are known to be susceptible, with many developing high serum titres (Kleiboeker 2011). The widespread occurrence of Culex species combined with dispersal via migratory birds has facilitated a near global distribution of WNV. Following transmission to a susceptible avian host, WNV is believed to initiate an infection in dendritic cells in the skin. Virus is subsequently transported to the draining lymph nodes and disperses via the bloodstream. Infection can then establish in the peripheral organs, with the virus eventually gaining entry into the central nervous system (Gamino and Hofle 2013). Although relatively little is known about the pathology of the virus in wild bird populations, a 1991 outbreak of WNV in New York resulted in severe disease and death in a variety of bird species. Amphibians, reptiles and mammals are also susceptible to infection, although they tend to be dead-end hosts, rarely developing sufficient viremia to re-infect mosquitos. In humans the majority of WNV infections are asymptomatic, but in approximately $1 \%$ of cases a severe neuroinvasive disease can occur resulting in encephalitis, meningitis or flaccid paralysis (Petersen et al. 2013).

\section{Avian poxviruses}

The avian poxviruses (genus Avipoxvirus: Poxviridae) are a group of enveloped double-stranded DNA viruses that cause disease in a broad range of bird species (Ruiz-Martinez et al. 2016). Infections are acquired when virus enters a break in the skin of a susceptible bird, which may occur through a variety of means including the bite of an insect vector, direct contact with an infected bird, or contact with contaminated fomites-a transmission route aided by the capacity of avian poxviruses to persist in the environment for many months (LaPointe 2010). Mosquito transmission is typically by Culex or Aedes species, with females feeding on viral lesions and mechanically transferring virus to other birds during subsequent bloodmeals. Avian poxvirus infections typically result in a mild and self-limiting disease in wild birds. 
However, epizootics among endemic island bird populations are often associated with more severe infections. Disease can manifest in cutaneous (dry pox) and diphtheritic (wet pox) forms. Cutaneous infection typically results in the development of proliferative lesions on the skin surrounding the cere, digits and feet (Thiel et al. 2005), and range in size from small nodules to tumour or wart-like masses. Although not usually directly fatal, cutaneous lesions can result in the impairment of vision, feeding or mobility, and may lead to more dangerous secondary bacterial and fungal infections. The diphtheritic form is less common, but is generally associated with higher mortality rates, and results in the formation of plaques in the mucosal membranes of the respiratory and digestive tracts. This can lead to emaciation from feeding difficulties, and congestion and/or haemorrhaging in the lungs.

\section{Main text}

\section{Insular areas at risk of $C x$. quinquefasciatus-associated avian biodiversity loss HAWAI'I}

The Hawaiian archipelago $\left(18^{\circ}\right.$ to $28^{\circ}$ North) is separated from the nearest continental landmass by approximately $4000 \mathrm{~km}$. Mean temperatures in Hawaii i range from 26 to $31{ }^{\circ} \mathrm{C}$ although considerable variation is seen dependent on elevation (maximum $4000 \mathrm{~m}$ ) and aspect, with four out of five Köppen climate types present (Anonymous 2020). Most species that are present in Hawai'i today are the result of recent $(<5 \mathrm{Ma})$ colonization from outside the archipelago, while some lineages that arrived earlier (e.g. 5-26 Ma) dispersed from older to younger islands (Price and Clague 2002). Due to their geographic isolation, the Hawaiian islands have fewer taxonomic groups compared to less isolated islands (Fleischer et al. 1998), however, the archipelago is characterized by remarkably high rates of endemism (Roderick and Gillespie 1998; Veron et al. 2019). At least four different passerine bird families naturally colonized Hawai'i, of which one, Hawaiian honeycreepers (family Drepanididae), is widely known for variation in plumage coloration, and in bill and tongue morphologies associated with specific feeding strategies (Freed et al. 1987; Lerner et al. 2011). Phylogenetic analysis shows that the honeycreeper radiation began approximately 5.7 Ma (Lerner et al. 2011), over which time these species evolved in isolation from mammalian predators and avian diseases that were more common on continental landmasses. As with many island species, this evolutionary isolation resulted in Hawaiian honeycreepers being particularly vulnerable to introductions of non-native species, and has contributed to them being among the world's most threatened forest bird groups (Buchanan et al. 2011).
The first written record of mosquitos in Hawai'i was made in 1826, and it is believed that mosquitos were first introduced earlier that year at Lahaina, Maui (Dine 1904; Pemberton 1964; Leong and Grace 2009). This record described an insect that caused a "singing in the ear", which was later identified as Cx. quinquefasciatus (Dine 1904). This species is now widespread throughout most of the Hawaiian Islands where it occurs across a large elevational gradient from coastal areas up to ca $1800 \mathrm{~m}$ above sea level (Pemberton 1964; Winchester and Kapan 2013; LaPointe 2000). Commonly occurring on Hawai $i$ in agricultural/domestic settings when oviposition sites are abundant, $C x$. quinquefasciatus is limited in its distribution on natural volcanic slopes where porous soils may reduce the presence of standing water (Lapointe 2008). However, its invasion into naturally forested settings has been aided by the rooting behaviour of Hawai 'i's widespread feral pigs which create sediment rich water-filled cavities when foraging on native tree ferns (LaPointe 2000; Goff and Vanriper 1980). Subsequent to this first accidental mosquito introduction, seven more species that were inadvertently introduced have also become established (Winchester and Kapan 2013). Three mosquito species, $C x$. quinquefasciatus, the yellow fever mosquito (Aedes aegypti; introduced circa 1890), and Asian tiger mosquito (Ae. albopictus; introduced circa 1900) are linked to disease transmission, however $C x$. quinquefasciatus is the most widely distributed and is the only mosquito species implicated in local disease transmission cycles involving local birds (LaPointe 2000).

By the time the causative agent of avian malaria, $P$. relictum, was introduced to Hawai' $i$ in the 1920s-1940s, $C x$. quinquefasciatus had become well established. Considerable evidence shows that Hawai'i's native forest birds, especially the iconic Hawaiian honeycreepers, are highly susceptible to this disease (e.g., (Atkinson et al. 1995; Samuel et al. 2011). There is also an association between honeycreeper abundance and elevation (Samuel et al. 2011; Warner 1968; Riper et al. 1986), whereby birds are better able to survive at higher elevations where cooler temperatures negatively impact both mosquito presence and Plasmodium development (Atkinson et al. 1995; Samuel et al. 2011). While there were once over 100 native forest bird species in Hawaii, only 21 continue to persist. Of these, 12 are either endangered or threatened, surviving mainly as small, fragmented populations limited to high-elevation areas beyond the reach of disease transmission.

In addition to avian malaria, $C x$. quinquefasciatus has also been strongly implicated as the primary vector of avian poxvirus amongst native birds in Hawai $i$, which shows similar epidemiological behaviour to avian malaria when assessed across temporal and elevational gradients 
(Samuel et al. 2018). While historical accounts attribute a high pathogenicity to avian poxvirus in Hawai $i$, and experimental introduction of avian poxvirus into populations of birds from more isolated Hawaiian islands has resulted in high rates of mortality (Warner 1968), it is likely that the current population-level effect of this disease on the main Hawaiian islands is limited, perhaps due to resistance developed from historical infections. Of note, however, is the strong association between chronic malaria infection and both active and old (healed) pox lesions, with one hypothesis put forward for this association being a synergistic relationship between these two pathogens, possibly on the immune functions of infected birds (Samuel et al. 2018).

Perhaps due to the devastation wreaked by avian malaria, comparatively little has been written regarding the threat posed by WNV to Hawai 'i's avian communities. What research that has been conducted has shown that $C x$. quinquefasciatus populations on Hawai'i are competent vectors for WNV and a captive population of a Hawaiian honeycreeper species (Amakihi: Hemignathus virens) experimentally infected with WNV suffered $>31 \%$ mortality-with higher rates predicted in 'free-ranging' birds (Lapointe et al. 2009). With quantitative studies estimating a substantial risk of WNV entering Hawaii $\mathrm{i}$ through air traffic (Kilpatrick et al. 2004), WNV may pose a significant existential threat to already struggling avian communities.

The first coordinated efforts at mosquito control in Hawai'i likely began with the formation of the "Hawai' $i$ Citizens Mosquito Campaign Committee" in 1904 (Pemberton 1964). However, most efforts have targeted localized disease outbreaks in humans associated mainly with Aedes species, partly because the larger landscape-level control necessary for conservation purposes is technologically difficult and expensive (Anonymous. 2017). In September of 2016, local, national, and international experts gathered to discuss novel approaches and emerging technologies that may be able to mitigate mosquitoborne diseases in Hawai' $i$, including avian diseases (Anonymous. 2017). Strategies discussed included traditional sterile insect techniques (SIT), as well as more novel incompatible insect technique (IIT) and geneticsbased strategies. At that time Wolbachia was identified as the tool to immediately begin evaluating, because Wolbachia male-based insect control programs had been successfully applied elsewhere, including within the USA (Atyame et al. 2015, 2016; Mains et al. 2016; Waltz 2016). A steering committee for landscape-scale mosquito control was established to develop a framework for possible use of this technology in Hawai' $i$, including outlining and pursuing components of research and development, communication and outreach, and adherence to federal and state regulations. This project has been able to gain substantial momentum thanks in large part to multiagency and multi-stakeholder involvement, the current state of Wolbachia technology, and the recognition of the immediate crisis facing Hawai'i's forest birds. While the potential of developing and releasing at least one type of gene-edited malaria-resistant honeycreeper, a strategy known as facilitated adaptation, was more recently evaluated (Samuel et al. 2020), such an approach would have substantial technical challenges and costs by comparison to development and implementation of mosquito control technology. With climate change currently reducing both the stability and size of Hawai'i's high elevation diseasefree refuges (Atkinson et al. 2014; Paxton et al. 2016; Fortini et al. 2015; Liao et al. 2017, 2015), it is clear that immediate landscape-scale mosquito control is critical to the survival of much of Hawai'i's remaining forest bird community.

\section{NEW ZEALAND}

New Zealand is an archipelago extending from $34^{\circ}$ to $47^{\circ}$ South, and comprises two major islands (North Island and South Island) and numerous offshore islands and islets, most of which lie within $50 \mathrm{~km}$ of the coast. The total land area of New Zealand is just under 270,000 $\mathrm{km}^{2}$, which is second to only Japan in terms of Pacific archipelagos, while the nearest continental landmass, Australia, is over $1500 \mathrm{~km}$ away. The mean annual temperature of New Zealand is between 10 and $16{ }^{\circ} \mathrm{C}$ with a maximum elevation of $3754 \mathrm{~m}$ (Neall and Trewick 2008). The area now known as New Zealand began to separate from Gondwana ca $90 \mathrm{Ma}$ (Neall and Trewick 2008). The current avifauna, as of 2000, consists of 169 species that were present and breeding prior to first human contact, 16 species that have arrived naturally since then, and 37 species introduced by Europeans (Holdaway et al. 2001). New Zealand's avifauna, considered the most 'extinctionprone' in the world, is projected to experience some of the highest proportion of real and functional extinctions over the next 80 years (Tompkins and Poulin 2006; Sekercioglu et al. 2004).

The mosquito fauna in New Zealand consists of 13 endemic species, three introduced species, and two recently eradicated invaders (Belkin 1968; Cane and Disbury 2010). The introduced species include Ae. australis, Ae. notoscriptus, and Cx. quinquefasciatus. In addition to $C x$. quinquefasciatus, three endemic members of the genus Culex occur in New Zealand: $C x$. pervigilans, $C x$. asteliae and $C x$. rotoruae. All three species are closely related, with recent findings suggesting that $C x$. rotoruae may not be a separate species from $C x$. pervigilans (Cane et al. 2020). Additionally, these New Zealand species do not appear to be part of the Cx. pipiens complex as 
once thought (Cane and Disbury 2010). While Cx. asteliae and $C x$. rotoruae are more isolated to certain parts of the North Island, Cx. pervigilans is the most prevalent and widespread mosquito in New Zealand, and is found throughout the country, including the Chatham Islands. While Cx. quinquefasciatus occurs throughout most of the North Island, its southern range appears to be limited to the northern part of the South Island, with occasional interceptions of non-established individuals at ports and airports further south (Belkin 1968; Cane and Disbury 2010). Culex quinquefasciatus was the first recorded exotic mosquito to be established in New Zealand, collected prior to 1848 , and is suggested to have arrived from American whaling vessels (Belkin 1968; Derraik 2004). However, only in the last 50 years has $C x$. quinquefasciatus expanded beyond its original sites of introduction in the northern part of the North Island (Holder et al. 1999), possibly due to an increase in temperature over this period (Tompkins and Gleeson 2006). Due to the cooler climate in New Zealand, Cx quinquefasciatus is only active in the warmer months, overwintering as larvae from May to September (Kramer et al. 2011).

Only one arbovirus, Whataroa virus (genus Alphavirus: Togaviridae), is known to actively circulate within New Zealand. Whataroa virus is established in bird populations along the west coast of the South Island and is transmitted by the native mosquitos $C x$. pervigilans and Culiseta tonnoiri (Kramer et al. 2011). Avian poxvirus is also present in New Zealand birds, with an increase in observations over the last two decades (Alley and Gartrell 2019). Sandflies (Diptera: Simuliidae) have been implicated in the spread of avian poxvirus in New Zealand although the exact contribution of these and other potential vectors, including $C x$. quinquefasciatus remains unexplored. Interestingly, as in Hawai' $i$, significant positive associations between avian poxvirus and avian malaria infection (i.e. concurrent infections) have been reported. Additionally, studies have demonstrated that New Zealand populations of $C x$. quinquefasciatus are competent vectors for the bird-mosquito-bird cycling WNV and Murray Valley encephalitis virus (genus Flavivirus: Flaviviridae), even at the cooler temperatures representative of New Zealand's climate (Kramer et al. 2011).

Of the mosquito-borne diseases currently present in New Zealand, however, avian malaria is considered of greatest concern in regards to the native avifauna. Like Hawai'i, New Zealand's endemic avifauna appear to be highly susceptible to avian malaria, leaving fewer birds surviving to the chronic phase of infection. Avian malaria has been diagnosed as the cause of death of multiple threatened species, captive and wild, including two species of kiwi (Apteryx spp.) (Schoener et al. 2014). Additionally, this disease has played a role in the deaths of birds translocated within New Zealand, complicating conservation efforts (Alley et al. 2008, 2010).

In New Zealand, avian malaria prevalence is often reported as higher in non-native species introduced from Europe and elsewhere, with these species likely acting as the primary reservoir for infection, to which spillback to native species can occur (Tompkins and Gleeson 2006; Niebuhr et al. 2016). Comparisons between historical and contemporary surveys of avian malaria suggest that the incidence of this parasite has increased over the ca 50 years between analyses (Tompkins and Gleeson 2006). One such study noted a positive association between avian malaria prevalence and the latitudinal distribution/expansion of $C x$. quinquefasciatus, leading authors to suggest that this introduced vector may be a cause of disease emergence (Tompkins and Gleeson 2006). Similarly, as in Hawai i $i$, malaria prevalence has been negatively associated with increasing elevational gradients (Niebuhr et al. 2016) where both mosquito density and malarial life-cycles are expected to be restricted. However, since avian malaria infections have been recorded outside of the latitudinal and elevational distribution of $C x$. quinquefasciatus but in the presence of the more cold tolerant $C x$. pervigilans (Tompkins and Gleeson 2006; Niebuhr et al. 2016), and also within forest canopy areas where $C x$. quinquefasciatus is largely absent (GudexCross et al. 2015), more information on abundance and vector competence of both species is needed to estimate their relative contributions to the observed trend of increasing malarial infections. If $C x$. quinquefasciatus is a more competent malaria vector than $C x$. pervigilans, or its ecology allows it to establish additional transmission-cycles, then any potential spread throughout New Zealand of this species may pose a serious threat to the avifauna present.

Mosquito control in New Zealand is largely 'traditional', relying on border surveillance to prevent new arrivals (Ammar et al. 2019), removal of artificial breeding sites and conventional pesticide usage to reduce population densities (Derraik 2005; Goldson et al. 2015). Successful eradication of two invasive mosquito species Ae. camptorhynchus and $C x$. sitiens has been achieved through use of pesticides relatively soon after mosquito detection (c. 2 years in both cases) (Garner et al. 2004; Yard 2011; Zealand 2020). Such an appetite to tackle invasions bodes well for the potential control of $C x$. quinquefasciatus in New Zealand, which would likely pose a more significant challenge due to its widespread distribution. To our knowledge there are no active programmes exploring genetic control for mosquitos in New Zealand, however, a radiation-based SIT programme was deployed as part of the successful eradication of the invasive painted apple moth (Teia anartoides) from West Auckland in 2003 
(Suckling et al. 2007) while, more recently, modelling approaches have been utilised to explore the feasibility of genetic control against invasive common wasps (Vespula vulgaris) (Lester et al. 2020). Previous use and exploration of these technologies in New Zealand suggests that their potential extension to $C x$. quinquefasciatus control is not implausible.

\section{GALÁPAGOS}

Straddling the equator, the Galápagos archipelago consists of 13 major islands larger than $10 \mathrm{~km}^{2}, 19$ smaller islands, and numerous islets located $1000 \mathrm{~km}$ west of mainland Ecuador. For most of the year, Galápagos is characterised by a hot, semi-arid climate with increased precipitation and lower temperatures occurring in highland regions (maximum elevation $1700 \mathrm{~m}$ though majority of islands are less than $500 \mathrm{~m}$ ). Average temperatures range from 21 to $30{ }^{\circ} \mathrm{C}$. The age of the islands decreases westward along the archipelago; the south-east island of San Cristobal is estimated to have emerged between 2.35 and 4.04 Ma (Cox 1983) while the western island of Fernandina emerged 35,000 years ago (White et al. 1993). The lack of a historical land bridge and its geographical isolation from mainland South America is evidenced by the archipelago's high endemism and low biodiversity. For example, land birds constitute 29 resident species of which 22 are endemic and 4 are endemic to the level of subspecies. Sea birds comprise 48 species of which 19 are resident (Swash and Birds 2005). Given this isolation, introduction of novel diseases is considered a serious and ongoing threat to avian communities in the Galápagos (Deem et al. 2012; Wikelski et al. 2004).

Three mosquitos are known to transmit diseases in Galápagos; two of these are implicated in transmitting pathogens to avifauna. Arriving ca 200,000 years ago, Aedes taeniorhynchus is known to inhabit mangrove habitats/salt marshes (Bataille et al. 2009) and is able to tolerate brackish water. This species is widespread across the Galápagos, being present on all islands sampled, primarily along coastal area (Eastwood et al. 2013). Bloodmeal analysis suggests Ae. taeniorhynchus feeds mainly on mammals and reptiles and may show an aversion to feeding on birds (Bataille et al. 2012) a pattern corroborated by later work (Asigau et al. 2019). However, evidence of avian parasites in wild-caught Ae. taeniorhynchus suggests bird feeding must occur at least at some low level (Bataille et al. 2012). Cx. quinquefasciatus is estimated to have established Galápagos populations in 1985 (Whiteman et al. 2005). As a freshwater obligate, preliminary studies only recorded populations close to lowland centres of human habitation where artificial water sources are plentiful (Whiteman et al. 2005). However, subsequent monitoring efforts observed this species in highland and northerly, uninhabited areas of Santa Cruz (Eastwood et al. 2019) and also on the uninhabited island of Santiago (Asigau et al. 2017), suggesting the worrying possibility that the distribution of this species may be expanding across the archipelago. Only one study assessing bloodmeals has been conducted on $C x$. quinquefasciatus in Galápagos which found an almost exclusively human-dominated diet. However, as this species was primarily encountered in areas of human habitation, the authors suggest caution over extrapolating these results to other, less inhabited areas (Asigau et al. 2019). Ae. aegypti, a recent arrival in 2001, is highly anthropophilic and since it displays a strong preference for feeding on humans, it is not considered a concern for wildlife disease.

With its endemic avian communities still entirely intact, the Galápagos has so far been spared the devastation experienced in other insular areas, however two avian diseases of primary concern in the Galápagos are WNV and avian malaria (Wikelski et al. 2004). West Nile Virus has not yet been detected in the Galápagos (Eastwood et al. 2014), however, populations of both $C x$. quinquefasciatus and Ae. taeniorhynchus from the Galápagos have demonstrated competency to WNV in lab experiments (Lapointe et al. 2009; Eastwood et al. 2013, 2011; Sardelis et al. 2001). As this virus has already been responsible for mortality in $>300$ bird species in North America (Marra et al. 2004) and Galápagos bird populations are thought to have evolved in the total absence of flavivirus infection pressure (Eastwood et al. 2013), there is serious concern that introduction could lead to population-level effects. Feeding patterns of Culex mosquitos in Galápagos are diverse (Asigau et al. 2019) and their broad diet elsewhere indicates that it could act as a bridge vector for WNV between birds and mammals (e.g. infected humans) (Hamer et al. 2009; Molaei et al. 2006; Zinser et al. 2004). Predictive modelling for WNV introduction to Galápagos demonstrated air transportation of tourists from Ecuador as the highest risk of arrival for infectious mosquitos (Kilpatrick et al. 2006). As signals of past WNV infection have recently been detected in equine surveys in coastal Ecuador (Coello-Peralta et al. 2019), increased vigilance for introduction to the Galápagos is required.

Conversely, multiple lineages of avian malaria have been reported in the Galápagos. Three of these (local nomenclature: lineages $\mathrm{B}, \mathrm{C}$ and $\mathrm{D})$ are likely not established, while lineage $\mathrm{A}$ is found in multiple species and sites and across multiple sampling years and is likely actively circulating (Levin et al. 2013; Palmer et al. 2013), albeit with a 'spotty' distribution. A finding consistent across studies is the inability to observe gametocytes (the mosquito-infectious 
stage) of Plasmodium in any blood smears analysed suggesting that endemic bird species targeted so far are likely 'dead-end' hosts. The identity of the 'reservoir' hosts capable of maintaining the development of avian malaria pathogens to the infective stage remains unknown. Interestingly, one study observed a clustering of avian malaria prevalence on islands with freshwater sources and near dense human habitationpossibly implicating the known avian malaria vector $C x$. quinquefasciatus in transmission of these parasites. Ae. taeniorhynchus is not known to be an avian malaria vector. However, amplification of mitochondrial sequences of Plasmodium DNA isolated from this species matches with Plasmodium lineages found in Aedes mosquitos in Socorro Island, Mexico (Carlson et al. 2011) and in Galápagos penguins (Spheniscus mendiculus) (Levin et al. 2013). With the relatively low highlands of the Galápagos islands unlikely to act as stable refuges against malaria spread (Asigau et al. 2017), as was historically the case in Hawai' $i$, the introduction of a more pathogenic and/or transmissive lineage of Plasmodium poses a continued threat to this archipelago.

Assessment of historical collections suggests that the Avipoxvirus group has been present on the Galápagos since at least 1899 and contemporary infections in endemic species can be mild or highly pathogenic depending on virus strain and host (Parker et al. 2011). Endemic avifauna impacted by canary poxvirus (a form of avian poxvirus) include Galápagos mockingbirds, yellow warblers, waved albatrosses and several species of Darwin's finches (Thiel et al. 2005; Tompkins et al. 2017; Vargas 1987). Molecular analysis reveals two strains of canary poxvirus present in wild birds in Galápagos and a third in chickens (Thiel et al. 2005). Although the exact vectorial pathways of Avipoxvirus in the Galápagos remain unknown, $C x$. quinquefasciatus is suspected to play a role (Asigau et al. 2017).

Control efforts aimed at Cx. quinquefasciatus in the Galápagos include fumigation of incoming aeroplanes in order to reduce risk of introducing previously infected females, traps and non-attractive lighting on inter-island boats and public information campaigns to remove potential oviposition sites (Anonymous 2020). The Galápagos has no history of genetic control use, however, use of the SIT has been proposed, and research is ongoing regarding potential use of this technology to control the invasive parasitic fly Philornis dowsi (Causton et al. 2013), suggesting an appetite for novel control methods for conservation purposes on the archipelago. Currently, the Galápagos National Park and the Charles Darwin Research
Centre have combined efforts to ensure the protection of the archipelago's fragile ecosystem. However, since the archipelago is highly driven by the tourism industry, routes of transportation will have to be carefully monitored to better manage foreign pathogens and their arthropod vectors.

\section{Genetic and Wolbachia-based options for $C_{x}$. quinquefasciatus control}

\section{Genetic control-an introduction}

Genetic control, also known as Genetic Pest Management or Genetic Biocontrol, is a pest management technique that involves introducing heritable modifications into wild populations of a target species in order to reduce the harm they cause. These modifications take different forms and can comprise, for example, engineered transgenes, radiation/chemically-induced mutations, or endosymbionts such as Wolbachia. Captive populations of the target species are manipulated to incorporate the modification, and are then released into the field, where they introduce the modification into the wild population via mating. The goal of these releases varies according to the design. For example, in 'population suppression' strategies, releases could aim to reduce the density, or locally eradicate a target population-e.g. through introducing a modification which causes non-viable progeny. Alternatively, in the case of some disease vectors, 'population modification' strategies (also known as 'population replacement') aim to leave their target populations intact but reduce pathogen transmission competency. Depending on the technology chosen and the design implemented, modifications may be introduced into wild populations that are either rapidly selected against and disappear ('self-limiting' designs), or persist, perhaps even spreading through, or beyond, the target population ('self-sustaining' designs-also known as 'gene drives') (Harvey-Samuel et al. 2017; Sinkins and Gould 2006; Alphey 2014; Burt 2003). The characteristics of these alternative designs have several practical ramifications varying from the number of releases required to achieve the desired effect, to the social and regulatory outlook on such interventions (Webber et al. 2015; Oye et al. 2014).

Within each of these broad categories (i.e. population suppression/modification, self limiting/sustaining) there exists an array of designs for achieving a similar effect on the target population (Fig. 1). For example, self-limiting population suppression can be achieved through inducing a deleterious phenotype (e.g. lethality) in both sexes (bisex RIDL (Phuc et al. 2007), or Wolbachia-based IIT (O'Connor et al. 2012)), or only in females (femalespecific RIDL (fsRIDL) (Jin et al. 2013; Ant et al. 2012; Leftwich et al. 1792; Fu et al. 2010)). A further variation includes the autosomal X-chromosome shredder (Galizi 

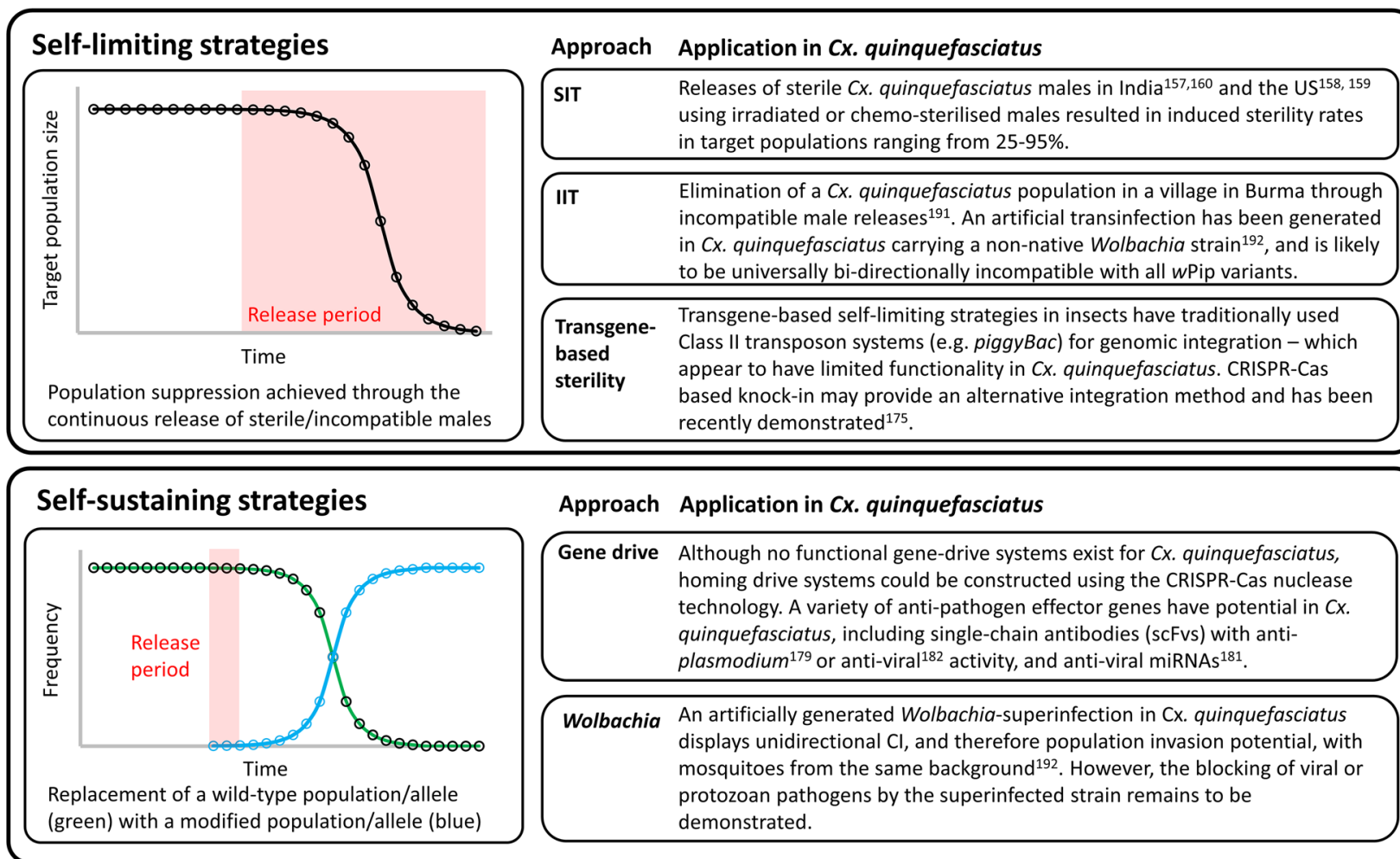

Fig. 1 Genetic control options for Culex quinquefasciatus. SIT: Sterile Insect Technique. IIT: Incompatible Insect Technique. Cl: Cytoplasmic Incompatibility

et al. 2014) which results in almost $100 \%$ male progeny from transgenic males, $50 \%$ of which are themselves transgenic. This system therefore relies on a skewing of the sex ratio towards males to affect target population density, rather than the killing off of females (or females and males), as in the two former strategies. A more persistent suppression system that is still self-limiting includes variants of the 'y-linked editors' (Burt and Deredec 1883). Here, a male-linked transgene (located on the Y-chromosome) could, for example, target a gene required for female viability, or include a gene whose expression results in non-viability of female offspring (Backus and Gross 2016; Godwin et al. 1914) such that all female progeny of a transgenic male are non-viable, while all male progeny are viable and transgenic. Readers may find Fig. 1 in our previous publication (Harvey-Samuel et al. 2017) helpful in understanding the differences between these and other self-limiting suppression options.

For self-sustaining gene drives, the mechanism by which a transgene or other inherited component achieves autonomous spread can itself differ substantially between designs. For example, a diverse group including engineered underdominance (Davis et al. 2001; Reeves et al.
2014) /UD ${ }^{M E L}$ (Akbari et al. 2013), TARE (Champer et al. 2020) / ClvR (Oberhofer et al. 2019) (and variations thereof (Champer et al. 2020)), killer-rescue (Gould et al. 2008), SDKR (Edgington et al. 2020), Wolbachia (Hoffmann et al. 2011), Medea (Chen et al. 2007) and engineered reciprocal translocations (Buchman et al. 2018) can very broadly be described as 'toxin-antidote' drives in that they operate through various means to create a rescuable genetic load in a target population. Orthogonal mechanisms to induce drive spread include the 'cut, copy and paste' mechanism of nuclease-based homing drives where a homologous chromosome is cut by the drive allele, with that drive allele being copied across into the cut site during the chromosomal repair process (known as 'homing') (Burt 2003). Such a homing drive could be used to spread a linked 'cargo gene' which reduces vectorial capacity (Gantz et al. 2015) (see Anti-pathogen transgenes section below), or may be designed to home into and disrupt a recessive female viability gene, creating a genetic load in females as it spread through a population (Hammond et al. 2016). Alternatively, a self-limiting autosomal X-shredder as described above could be converted to a suppression drive by relocating the transgene to the Y-chromosome (or potentially other male-linked 
chromosomal regions), such that transgenic progeny are close to $100 \%$ male, all of which are themselves transgenic (Burt 2014).

While not exhaustive, this discussion provides a glimpse of the various designs that would be open to researchers interested in exploring genetic control options in $C x$. quinquefasciatus. The prioritisation of which, if any, of these myriad options is most appropriate for targeting this species would need to take place in conjunction with experts familiar with the local communities, ecologies and geographies of potential release locations. However, with at least proof-of-principle demonstration of most of these strategies in other mosquitos or Drosophila melanogaster, there appears to be little a priori evidence to suggest that their exploration in $C x$. quinquefasciatus would be technically unfeasible. One possible exception to this is extension of the 'X-shredder' technologies. These rely on the targeted destruction of $\mathrm{X}$-chromosomal loci in the male germline (in this case, the chromosome destined to 'determine' the female sex of all progeny inheriting it), resulting in its probable exclusion from the functional sperm pool. Cx. quinquefasciatus, like Ae. aegypti, does not possess divergent sex chromosomes but instead, a dominant, male sex-determining region (the so called ' $\mathrm{M}$ locus') on chromosome 1 , which is otherwise homomorphic between males and females (Ruzzante et al. 2019). This would likely reduce the number of sequences which could be targeted exclusively on chromosomes destined for hypothetical female progeny.

In general, genetic control strategies incorporate features that make them attractive for the eradication of an invasive pest (Harvey-Samuel et al. 2017; Godwin et al. 1914; Teem et al. 2020). Perhaps uniquely, they increase in efficacy as the target population declines, making them ideally suited to driving populations to extinction, and can be used in combination with more traditional technologies such as breeding site reduction or insecticide fogging, whose efficiency is expected to drop as target individuals become increasingly scarce. This aspect of genetic control derives in part from the fact that the control agent is itself a living organism, biologically programmed to seek out individuals in the target population. This is particularly advantageous to invasive species control, where target populations may exist over wide areas of inaccessible terrain or where there are multiple, small landowners, making traditional interventions difficult and expensive. Additionally, the 'area-wide' nature of genetic control programmes allows them to be used at spatial scales that may be helpful in preventing immigration or re-invasion into a target area during an eradication attempt, which has proved a serious challenge using more traditional methods.
As genetic control relies on mating to impact a target population, it is considered a species- specific option, relative to many 'traditional' control technologies. This characteristic is a double-edged sword, however, as, while it may be advantageous in limiting off-target effects (especially pertinent in areas of high biological value), if a particular disease is spread through more than one vector or mechanical route, then removal of a specific pest may not be sufficient to halt transmission cycles (Alphey et al. 2010).

In addition to the theoretical benefits of these technologies, there are a number of concerns regarding their potential deployment in the wild, and in particular, the use of the 'self-sustaining' gene drives (Webber et al. 2015; Brossard et al. 2019; Esvelt and Gemmell 2017). Specifically, two ecological 'off-target' concerns are that a heritable modification could spread into a non-target population of the target invasive species (e.g. a population where that species is native), or spread of the modification into a closely related species following interspecific hybridisation (Harvey-Samuel et al. 2017; Teem et al. 2020). Detailed discussion of the real-world probability of these risks has been undertaken elsewhere (Panel EG 2013), including molecular and field-trial designs that could theoretically reduce their likelihood (Harvey-Samuel et al. 2019). An additional example of a theoretical risk which would apply to both human and animal populations within a target release area are the potential allergenic effects of being bitten by modified vectors (Reeves et al. 2005). A consensus that has clearly emerged from the literature on the potential deployment and regulation of such technologies is that the benefits and risks of their use should be weighed up on a case-by-case basis (Oye et al. 2014; James 2005; Adelman et al. 2017; Collins 2018; NASEM 2016; Long et al. 2020), and frameworks for such risk-assessment have emerged for exactly this purpose (Turner et al. 2018; Hayes et al. 2018; David et al. 2013; Benedict et al. 2008). Such a risk-assessment framework was employed prior to the first field deployment of $\mathrm{Wol}$ bachia (Murphy et al. 2010), the first and still the only self-sustaining technology to be deployed. Subsequent to this first deployment, 'problem-formulation' frameworks have been utilised to inform risk assessment for potential use of GM gene drive A. gambiae in sub-Saharan Africa (Roberts et al. 2017). Any deployment of these technologies in the insular environments explored above would require similarly thorough prior assessment.

\section{Current status of genetic control technologies in $C x$. quinquefasciatus}

The behaviours and merits of various genetic control designs have been thoroughly explored elsewhere (Champer et al. 2016; Marshall and Hay 2012; Leftwich 
et al. 2018) and are not further discussed here. Instead, here we discuss the current state of the underlying technologies on which these genetic control systems are built with regards to $C x$. quinquefasciatus with a focus on options for genetic modification, and transinfection using the endosymbiont Wolbachia. Additionally, we provide a brief exploration of molecular means by which $C x$. quinquefasciatus may be engineered with 'anti-pathogen' transgenes against two diseases of primary concern-Avian malaria and WNV.

\section{Genetic modification of $C x$. quinquefasciatus}

Radiation/chemosterilisation The paradigmatic example of genetic control (Sterile Insect Technique: 'SIT') utilises ionizing radiation to induce random doublestranded breaks in the DNA of captive insect populations prior to their field release. Ideally, a dose of radiation can be administered which effectively sterilises those insects that are released but does not severely impact their mating competitiveness. Culex quinquefasciatus has been the subject of several field test programmes assessing the efficacy of radiosterilised male releases. In northern India in the early 1970 s, two small-scale, short-term release trials of radiation-sterilised male pupae were conducted. These trials conducted in the villages of Sultanpur and Pochanpur for four and six weeks, respectively, were able to generate a significant but modest level of sterility in the wild population (up to $25 \%$ and $75 \%$ ) (Patterson et al. 1975). A similar trial was also conducted in 1973 on Seahorse Key, $3 \mathrm{~km}$ off the coast of Florida. Here males were irradiated as adults immediately prior to release in an attempt to improve mating competitiveness, possibly explaining the increased sterility induced in the target population over the c. 4 month trial (up to 84\%) (Patterson et al. 1977).

Concerns over the mating competitiveness of radiosterilised male mosquitos led to research into alternative technologies to induce similar DNA damage including the use of chemosterilants. The alkylating agent thiopeta was trialled as one such technology for $C x$. quinquefasciatus. In 1968-1969, also on Seahorse Key, male $C x$. quinquefasciatus which had been treated with aqueous thiotepa as pupae were released (Patterson et al. 1970). High levels of sterility (up to 95\%) were induced in the wild population over the 10 week trial leading to the elimination of the island's larval population (immigration from surrounding areas prevented elimination of the adult female population). In 1973, a larger trial was conducted in the village of Dhulsiras, Northern India (Yasuno et al. 1975). Here, up to 300,000 treated males were released daily for more than five and a half months. Although high levels of sterility (80-90\%) were briefly induced in the wild population, overall sterility levels were considered very low, which was explained by the immigration of mated females into the trial site from surrounding areas.

Although moderately successful, these trials did not progress to full-scale suppression programmes, as has been the case for other insect pests (Klassen and Curtis 2005). It is unclear exactly why this was the case, though continuing issues surrounding male mating competitiveness, environmental concerns over the mass use of chemosterilants and the political climate in potentially suitable countries have variously been cited as reasons for the stalling of these technologies (Klassen and Curtis 2005; Lees et al. 2015). The revolution in methods for engineering insect genomes which began in the late twentieth century allowed a resurgence of interest in genetic control (Alphey et al. 2010). The current state of these new technologies in $C x$. quinquefasciatus will be discussed below.

Transposon-based genetic engineering Transgenic modification of insects-i.e. the genomic integration of exogenous DNA sequences-traditionally relies on the use of Class II transposable genetic elements (transposons/ jumping genes) (O’Brochta et al. 2003). Transposons from this class mobilise through a 'cut-and-paste' mechanism, excising themselves from the genome and integrating at a second location. This ability has been harnessed to genetically engineer a wide range of insect species with the exogenous sequence of interest placed within the recognition sequences of a transposon on a synthetic plasmid and injected into the developing germline along with a source of transposase (the enzyme which catalyses the cut and paste reaction).

Development of such transposon-mediated modification technologies in $C x$. quinquefasciatus has lagged behind other mosquito species. This is evident when comparing $C x$. quinquefasciatus with other Culicine mosquitos such as Ae. aegypti and Ae. albopictus, both of which are readily transformed (Gregory et al. 2016). Only two examples of $C x$. quinquefasciatus transformation have been published, each using the Hermes transposable element (Allen et al. 2001; Allen and Christensen 2004). While these demonstrated relatively high rates of transformation efficiency (c. 6-12\%), both resulted in the non-canonical integration of plasmid backbone sequence into areas of the genome flanking the sequence of interest-a finding also observed in the use of the Hermes system in Ae. aegypti, but not in other dipterans including D. melanogaster, Ceratitis capitata or Stomoxys calcitrans (Allen et al. 2001). Such behaviour is generally undesirable as it may lead to the integration of plasmid elements such as antibiotic resistance genes that may complicate the regulatory pathway for such lines in a field setting. Interestingly, the use of the piggyBac system-far 
and away the most commonly used insect transformation technology-appears to be unusually challenging in $C x$. quinquefasciatus, with no reports of the successful use of piggyBac at the time of writing. In contrast, published data exist describing a large number of unsuccessful attempts (estimated transformation frequency, if possible, of less than 0.5\%) (Anderson et al. 2019). Nonetheless, it is encouraging that a number of transgene-construction components commonly used in insect genetic modification have been demonstrated to function in $C x$. quinquefasciatus such as the Hr5/IE1 baculovirus promoter (Wilke et al. 2013). Spatial control of transgene expression has also been achieved through use of the $D$. melanogaster Actin $88 \mathrm{~F}$ flight-muscle specific promoter (Allen and Christensen 2004). These results indicate that the 'normal rules' governing transgene construction and function will apply to $C x$. quinquefasciatus if a more reliable means of transformation can be established.

CRISPR-Cas based genetic engineering The CRISPRCas system consists of a targetable endonuclease (Cas enzyme) and a short targeting RNA (sgRNA - single guide RNA). When present together, an sgRNA will complex with a Cas protein molecule and direct it to cleave DNA sequences with high complementarity to its own RNA sequence (Jinek et al. 2012). The CRISPR/Cas system has revolutionised functional genetics studies due to its high specificity and the ease with which it can be cheaply programmed and re-programmed to target different genomic sequences by simply introducing different sgRNAs.

CRISPR-Cas systems form the basis of a number of gene drives in which genes expressing the Cas and sgRNA components are integrated into the germline of the target organism, subsequently expressing, complexing and cleaving DNA within the cells of that organism over multiple generations (Esvelt et al. 2014). Besides this 'active genetics' use, CRISPR-Cas systems can also be used as tools for the integration of transgenes into a target genome, also referred to as transgene 'knock-in'. Here, alongside the injected Cas enzyme and sgRNA, a plasmid is supplied with a transgene of interest nested within sequences homologous to the genomic sequences flanking the target site cleaved by the Cas enzyme. Subsequent to cleavage, a cell may use this plasmid as a 'repair template' as it attempts to repair the cleaved genomic site allowing the transgene of interest to be simultaneously copied across into the genome. This allows the 'site-specific' integration of a transgene sequence as opposed to the semi-random nature of the transposon-based systems.

CRISPR-based systems are relatively well developed in $C x$. quinquefasciatus having been used in gene disruption ('knock-out'/reverse genetics) studies of the CYP9M10 gene (causing reduced pyrethroid resistance)
(Itokawa et al. 2016), and the white (Li et al. 2020), kmo (Anderson et al. 2019), cardinal, ebony and yellow genes (Feng et al. 2020) (causing disruptions to eye or body pigmentation). Although varying between studies, reported rates of inherited single allele disruption have been remarkably efficient (20\% (Itokawa et al. 2016), 78-93\% (Li et al. 2020) and 16\% (Anderson et al. 2019), respectively). One noticeable trend from these studies is that allele disruption rates appear to broadly correlate with injected embryo survivorship. Due to their 'raft-laying' oviposition behaviour, $C x$. quinquefasciatus are considered by some to be more difficult to inject at the embryo stage than other mosquitos such as Ae. aegypti whose eggs are laid singly and can be individually manipulated/orientated. A possible solution to this is through development of the ReMOT control technology (Chaverra-Rodriguez et al. 2018). Here, a fusion protein consisting of Cas9 adjoined to the P2C region from $D$. melanogaster Yolk Protein 1 (DmYP1) is injected into the haemolymph of adult female mosquitos. Yolk proteins are normally produced in the fat body, secreted into the haemolymph and subsequently taken up by receptors on the ovaries, ultimately being sequestered within the developing oocyte. In $A e$. aegypti the synthetic P2C-Cas9 was found to follow a similar course allowing editing of oocytes whilst still in the ovary. The P2C domain was found to exhibit similar behaviour in $C x$. quinquefasciatus-localising to the ovaries when injected into the haemolymph of adult females, although full gene editing experiments were not performed. If such a system could be validated for Cx. quinquefasciatus, and crucially, modified for gene knock-in (integration) rather than simple knock-out then this may prove an advantageous alternative to the challenge of embryonic injections in this species. Regarding CRISPR-Cas knock-in through traditional microinjection methods: this was recently demonstrated in Cx. quinquefasciatus, again targeting the kmo gene (Purusothaman et al. 2021). While the integration rate of the transgene into the $\mathrm{kmo}$ locus $(1.6 \%)$ provides hope that this may prove a relatively efficient alternative to transposon-based transgene integration in this species, this method will need to be further evaluated at other target sites within the genome.

Although not necessary for gene integration purposes, development of CRISPR-based gene drives requires a method for the expression of sgRNAs in vivo. Typically this is achieved through the use of Polymerase III (Pol III) promoters that produce RNA transcripts devoid of terminal regulatory modifications such as polyA tails and $5^{\prime}$ caps, making them ideal for the expression of short functional RNAs. A diverse panel of insect Pol III promoters have been validated in the $C x$. 
quinquefasciatus Hsu cell line for this purpose (Anderson et al. 2020). Further in vivo testing will be required to assess whether the magnitude and spatial/temporal expression characteristics of promising candidates are appropriate for specific gene drive designs.

Anti-pathogen transgenes One desirable outcome of a gene drive could be to spread a transgene that reduces the competency of the vector for a pathogen (known as a 'refractory' or 'anti-pathogen' transgene) to a high frequency. The literature on engineering avian malaria (Plasmodium gallinaceum) refractory transgenes in Ae. aegypti has been reviewed previously, and is a guide for what may be possible in $C x$. quinquefasciatus (HarveySamuel et al. 2017). In summary, although expressing single-chain antibodies (scFvs) to the P. gallinaceum circumsporozoite (Jasinskiene et al. 2007) and chitinase (Li et al. 2005) proteins in Ae. aegypti resulted in significantly reduced sporozoites, it is unlikely that either mechanism, on its own, would lead to full refractoriness. However, simultaneous targeting of human malaria (Plasmodium falciparum) homologues of these two proteins, again using scFvs, induced full refractoriness in Anopheles stephensi (no sporozoites produced upon challenge) (Isaacs et al. 2012). Encouragingly, this dual-scFv was capable of being driven to 'full introduction' (100\% of insects carry at least one copy of the transgene) in small cage populations within 6-8 generations using a CRISPR-Cas9 homing drive and a single 1:1 engineered: wild-type mosquito release (Pham et al. 2020).

More recently, significant progress has been made in engineering mosquito refractoriness to flaviviruses. For example, Ae. aegypti engineered to express a polycistronic, miRNA-like cluster targeting the Zika virus (genus flavivirus: Flaviviridae) RNA genome displayed full refractoriness (challenged mosquitos unable to transmit virus to susceptible mouse model) (Buchman et al. 2019). Using an orthogonal approach, Ae. aegypti was engineered to express a scFv which was broadly effective at neutralising all four serotypes of the Dengue virus (genus flavivirus: Flaviviridae) (Buchman et al. 2020). These results and those detailed above for malaria suggest a rich set of options for engineering refractory mechanisms in $C x$. quinquefasciatus to $P$. relictum and WNV.

Wolbachia The species Wolbachia pipientis, first described in the Cx. pipiens complex (Hertig and Wolbach 1924), are alphaproteobacteria that are widespread among arthropods. As obligate intracellular bacteria, they are transovarially transmitted from mother to offspring during oogenesis. Wolbachia commonly induce a pattern of crossing sterility known as cytoplasmic incompatibility
(CI), which results in inviable embryos when Wolbachiacarrying males mate with Wolbachia-free females-but which is rescued in Wolbachia-carrying females. Cytoplasmic incompatibility thereby imposes a frequencydependent fitness penalty on non-Wolbachia-carrying females and a corresponding relative fitness advantage for Wolbachia-carrying females. This produces a mechanism for invasion that allows Wolbachia to spread in populations provided critical threshold frequencies are surpassed (Turelli 2010; Turelli and Hoffmann 1991).

Releases of Wolbachia-carrying mosquitos are currently being trialled as a vector control intervention in two distinct ways. Firstly, the self-sustaining spread of certain pathogen-blocking Wolbachia strains through mosquito populations can significantly reduce vector competence and therefore potentially disease transmission. Secondly, in a strategy closely analogous to SIT known as the incompatible insect technique (IIT), wild insect populations can be suppressed by overflooding with released males carrying Wolbachia strains that induce $\mathrm{CI}$ and therefore sterility with wild females without the need for the high radiation doses associated with SIT. The former strategy aims for the long-term replacement of wild populations with pathogen-blocking Wolbachia-carriers (Ryan et al. 2019; Nazni et al. 2019), while the latter attempts to achieve the local elimination of vector populations (Crawford et al. 2020; Zheng et al. 2019). Recent trials with laboratory generated Wolbachia transinfections in the major dengue virus vector $A e$. aegypti, a species that is not a natural Wolbachia-carrier, have generated promising results with both approaches. The stable establishment of Wolbachia has been reported in wild Ae. aegypti populations with subsequent reductions in dengue incidence (Ryan et al. 2019; Nazni et al. 2019), and suppression of an Ae. aegypti population has been achieved in an area of California, through the release of incompatible males (Crawford et al. 2020).

The $C x$. pipiens complex is naturally infected at close to fixation with Wolbachia strains belonging to the monophyletic $w$ Pip group. The strains comprising the $w$ Pip group show significant diversity in the genes encoding the $C I$ induction and rescue factors; populations of $C x$. pipiens carrying alternative $w$ Pip forms display natural variation in CI crossing patterns, with crosses of males and females carrying divergent forms of $w$ Pip resulting in either no CI (crosses are compatible in both crossing directions), unidirectional CI (where crossing is compatible in one direction, but not in the other) or bidirectional CI (both directions are incompatible) (Bonneau et al. 2018).

The presence of naturally-occurring bidirectionallyincompatible $w$ Pip variants in the $C x$. pipiens complex provides potential for incompatible male releases 
without requiring the artificial generation of novel Wolbachia-host associations through embryonic cytoplasmic transfers-a process that is technically challenging and laborious. This 'naturally-occurring' approach has been validated in caged experiments involving the simulated suppression of $C x$. quinquefasciatus populations through the release of incompatible $C x$. pipiens males (Atyame et al. 2015), and the local elimination of $C x$. quinquefasciatus from a village in Burma through the release of $C x$. quinquefasciatus males carrying an incompatible $w$ Pip variant (Laven 1967). A novel transinfection in $C x$. quinquefasciatus was recently generated carrying the $w$ AlbB strain of Wolbachia that naturally infects Aedes albopictus (Ant et al. 2020). The wAlbBcarrying strain induced fully penetrant bidirectional CI in test crosses with $C x$. quinquefasciatus carrying the Sri Lankan $w$ Pip (Pel) strain, and is thought likely to be incompatible with all $w$ Pip variants. The generation of a universally incompatible strain may be especially useful for $C x$. quinquefasciatus populations, such as those on the Hawaiian Islands, that may contain more than one $w$ Pip variant (Atkinson et al. 2016). Although incompatible Cx. quinquefasciatus strains currently exist and could in principle be utilised following introgression into the nuclear background of a local host, an IIT strategy would likely also need to incorporate mechanisms to avoid the inadvertent establishment of release strain females in the suppression zone. The replacement of an indigenous population with the foreign release strain could result, for example, through accidental releases of females arising from imperfect sex sorting. Several modifications have been proposed to mitigate the risk of this outcome, including the use of host chromosomal translocations that cause partial sterility from within-strain matings (Curtis 1985), the integration of IIT with irradiationwhere pupae are exposed to a relatively low doses of radiation prior to release that are sufficient to ensure sterility in females, but would be less than that required for full sterility in males (Patterson et al. 1975; Arunachalam and Curtis 1985), and the use of very high accuracy sex-sorting systems-IIT trials in California with Ae. aegypti have used an automated machine-learning based sex-sorter to reduce female contamination to an estimated one female out of every 900 million males (Crawford et al. 2020).

As an alternative strategy, the spread of pathogenblocking Wolbachia strains through wild populations of Cx. quinquefasciatus could be attempted; this would have the advantage of requiring a lower level of release than IIT, with the goal being a population with a stable high frequency of the Wolbachia transinfection that no longer transmits disease and is resistant to reinvasion. Spread is achieved using strains inducing either unidirectional or bidirectional CI, with thresholds for invasion expected to be higher under a bidirectional model. Strains generating both crossing types have been created in $C x$. quinquefasciatus. A transinfection with $w \mathrm{AlbB}$, a strain that causes strong dengue virus transmission blocking in Ae. aegypti (Ant et al. 2018; Flores et al. 2020) and Aedes polynesiensis (Bian et al. 2013a), and Plasmodium falciparum inhibition in Anopheles stephensi (Bian et al. 2013b), induced bidirectional CI with $w$ Pip in wild-type Cx. quinquefasciatus (Burt 2014). A superinfection was also generated in the Sri Lankan Pel Cx. quinquefasciatus wild-type line incorporating wAlbA (Burt 2014), a Wolbachia strain native to Ae. albopictus that had previously shown Zika virus transmission blocking following oral challenge in Ae. aegypti (Chouin-Carneiro et al. 2020). The wPip$w$ AlbA superinfection displayed full unidirectional $\mathrm{CI}$ in crosses with wildtype Cx. quinquefasciatus (Burt 2014), suggesting the potential for invasion and establishment in wild populations with the same wPip crossing type. However, these transinfected $C x$. quinquefasciatus lines have not yet been challenged with pathogens. While Wolbachia transinfections in Ae. aegypti have been shown to block WNV transmission (Joubert and O'Neill 2017), this capacity remains to be validated in Cx. quinquefasciatus. Moreover, it is doubtful that Wolbachia transinfections in $C x$. quinquefasciatus will block the transmission of avian poxvirus which is transmitted mechanically during bloodfeeding.

The inhibition of Plasmodium parasites by Wolbachia may be due to some or all of priming of the host innate immune system by the endosymbiont (Kambris et al. 2010), changes in lipid profiles (Geoghegan et al. 2017), or increased levels of reactive oxygen species (Pan et al. 2012). While strong innate immune priming has been observed in transinfections with non-native Wolbachia hosts such as Ae. aegypti (Moreira et al. 2009) and An. gambiae (Kambris et al. 2010), it was not observed in $C x$. quinquefasciatus (Ant et al. 2020), suggesting that any blocking of avian malaria by $w \mathrm{AlbB}$ in these transinfections may be limited if immune priming is the primary mechanism. Pathogen blocking by Wolbachia generally depends on the higher density and wider tissue distribution seen in non-native transinfections. $\underline{w}$ AlbB reached similar overall densities in Culex to the native $w$ Pip (Ant et al. 2020). However, $w$ AlbB and $w$ Pip are phylogenetically close, and other more distantly related Wolbachia strains may reach higher densities, as was observed when $w$ Mel was introduced into Ae. albopictus to replace the two native strains (Blagrove et al. 2012).

\section{Social acceptability}

Decisions on the suitability of a technology for a given situation typically requires the consideration of a variety of technical factors, as well as an assessment of the 
balance of ecological and human risks and benefits (Harvey-Samuel et al. 2019). Central to this judgement are the views of local stakeholder communities, whose socio-cultural beliefs and traditions concerning the environment and its fauna may differ significantly from those of the researchers and other parties responsible for implementing and overseeing the control strategy. This is especially true in the application of genetic technologies, particularly those involving genetic modification.

Effective community engagement is a particularly important dimension of genetic control on the islands of the Indo-Pacific tropics, a region with a long and troubling history of colonialism and sovereignty loss (Reed 2018). Researchers therefore have a duty to ensure that the use of a given strategy has real ecological value to local stakeholders, and is not merely a convenient test site to establish a proof-of-principle prior to mainland use, and that engagement promotes the mutual exchange of ideas and the integration of local values. A study of the views on genetic control methods involving indigenous Māori communities in New Zealand, for example, highlighted the importance of approaching engagement in a manner that promotes open dialogue and the exploration of local worldviews. Although New Zealand in general tends to have a strong anti-GMO legislative stance (El-Kafafi 2007), research suggests that resistance to genetic control among a segment of New Zealanders is, at least partly, shaped by opposition to authority and top-down initiatives, rather than the control methods per se (MacDonald et al. 2020). Thus, the researchers recommended that stakeholder engagement go beyond use of the information deficit model of engagement (an approach frequently employed in the communication of science, which involves the one-way flow of information from researchers to the public), which can be counterproductive and may exacerbate the polarisation of opinions (MacDonald et al. 2020). A separate study soliciting views on genetic modification and gene editing from Māori communities suggested that participants did not oppose the novel technologies a priori, but raised strong concerns around how and when they should be implemented, with the participants often referring to traditional Māori values and cultural concepts when giving opinions on the use and regulation of genetic technologies (Hudson et al. 2019). Using community engagement to develop an understanding of the underlying values associated with opinions towards novel control methods, and their integration into structured decision making, may therefore help mitigate potential conflict (Estevez et al. 2015). For instance, the spread of a self-propagating exogenous control factor (either a transgene or endosymbiont) through a wild mosquito population may be viewed as undesirable in some communities where the local habitat is valued as a wild haven. In such cases it may be possible to avoid the introduction of completely foreign factors-efforts in Hawaili, for example, are attempting to develop a Wolbachia IIT program using Wolbachia strains already present on the islands (Atkinson et al. 2016).

Effective community engagement is increasingly recognised as an integral component of transparent research, including in vector control (Macer 2005; Resnik 2018; Kolopack et al. 2015), with funding agencies placing ever more importance on structured stakeholder communication. It is therefore the responsibility of researchers and managers to ensure that genetic control strategies are only deployed after extensive consultation and dialogue with indigenous communities, and that these strategies are adapted as far as possible to account for local worldviews and culture.

\section{Conclusions}

The spread of $C x$. quinquefasciatus and the diseases it vectors pose a continuing threat to the unique avifauna communities of three insular biodiversity hotspots: Hawai $i$, New Zealand and the Galápagos. The nature and urgency of these threats differs depending on the biological and geographic circumstances of each area. In Hawai $i$, for example, it is clear that without immediate, concerted action to remove or reduce $C x$. quinquefasciatus populations, further loss of endemic avifauna will occur. This 'simple' conclusion can be made due to the intimate relationship between avian malaria (the established primary causative agent of decline) and Cx. quinquefasciatus (the only avian malaria vector currently established in Hawai i $i$ ). Although the Galápagos remains relatively devoid of such population-level effects, the recently recorded spread of $C x$. quinquefasciatus into non-inhabited areas/islands and crucially, the lack of stable, high-elevation refugia against this spread, imply potentially disastrous consequences should a pathogenic strain of WNV or lineage of avian malaria be introduced. In both these areas, a genetic control solution would be potentially advantageous as there is a single primary bird-biting mosquito present-either to remove $C x$. quinquefasciatus populations completely, or, ensure that refuges at particular altitudes or islands/islets remain disease free. A more complex situation is posed by New Zealand where $C x$. quinquefasciatus is one of multiple Culex species present. The exact contributions of these endemic Culex species and $C x$. quinquefasciatus towards malaria transmission are only circumstantially known and may differ in different areas/latitudes, and the overall contribution of avian malaria to the observed populationlevel decline of avian communities is less well established. Here, an engineered/Wolbachia-based solution would be most advantageous if the ecology of $C x$. quinquefasciatus 
provided unique transmission routes, for example by bringing it into contact more often with urban-dwelling non-native reservoir hosts. Another consideration unique here to New Zealand would be any potential negative impacts a genetic control programme targeting $C x$. quinquefasciatus may have on these endemic Culex species, and what concerns, if any, exist towards changes in the population status of these native mosquitos in New Zealand. What is clear from this case study is that more research is required to establish the precise threat to bird communities in New Zealand from Cx. quinquefasciatus. The difficulty in establishing such conclusions, even in an area as relatively well-studied as New Zealand, highlights the wider potential threat posed by $C x$. quinquefasciatus to smaller insular communities across the Pacific and Indian oceans where little or no research may yet have been conducted.

We highlighted significant technical gaps that will need to be addressed if a genetic control solution to this pest is to be found. This point is of particular urgency given the rapid projected decline of some insular avian communities and the relatively long periods of research and development, product testing/trialling and regulation required before these technologies can be used in the field. This is further exacerbated by the relative lack of focus on $C x$. quinquefasciatus to date, in respect of development of efficient rearing and microinjection methods, and also the low number of lab-adapted colonies, which would, at least initially, likely slow development of such systems in this pest. In terms of genetic modification, the primary goal should be the establishment of a system for the reliable engineering of the $C x$. quinquefasciatus genome. Research to date suggests that the piggyBac system-the workhorse of engineering insect genomes-displays significant limitations in $C x$. quinquefasciatus and future efforts should be focussed elsewhere. An initial demonstration of CRISPR-Cas knock-in in this species provides a potential alternative, but will require substantial further evaluation against other gene targets. Wolbachia transinfections may provide a quicker route to a genetic control strategy, especially if existing wPip-infected Cx. quinquefasciatus populations can be identified which are bidirectionally incompatible with those in each target area. However, this would require the simultaneous development of mass-sexing systems and it is likely that it would only be applicable to 'IIT or sterile-male' releases, rather than in a pathogen-blocking self-sustaining mechanism. Such a mechanism would require a novel transinfection, which again requires additional development and testing phases. There is no technical reason, however, for strategies involving genetic modification and Wolbachia to be viewed as mutually exclusive. Indeed, it may be beneficial to instigate use of 'rapid-deployment' technologies such as IIT or SIT in order to 'shore up' refuges or prevent continued spread to uninvaded islands within an archipelago, whilst simultaneously encouraging the development of longer-term, more sustainable solutions such as gene drives. Ultimately, it is only through objective consideration of all the technological options available that current threats to insular avian communities, such as those posed by $C x$. quinquefasciatus, will be resolved.

\begin{abstract}
Acknowledgements
Not applicable.

Authors' contributions

All authors contributed sections to the manuscript and approved the final version.

\section{Funding}

THS and LA were supported by core funding from the BBSRC to The Pirbright Institute [BBS/E///00007033, BBS/E///00007038 and BBS/E///00007039]. SS and TA were supported by Wellcome Trust Awards No. 108508 and No. 202888. JS was supported by National Science Foundation Grant No. 1345247. CNN was supported by Strategic Science Investment Funding from the New Zealand Ministry of Business, Innovation and Employment. SA and PP were supported by funding from the UMSL Des Lee Fund for Zoological Studies, the Whitney R Harris World Ecology Center and the Saint Louis Zoo Field Research for Conservation (FRC). Any opinions, findings, and conclusions or recommendations expressed in this paper are those of the authors and do not necessarily reflect the views of their respective funding bodies.
\end{abstract}

Availability of data and materials

Not applicable.

Declaration

Ethics approval and consent to participate Not applicable.

\section{Consent for publications}

Not applicable.

\section{Competing interests}

The authors declare no competing interests.

\section{Author details}

${ }^{1}$ Arthropod Genetics Group, The Pirbright Institute, Woking GU240NF, Surrey, UK. ${ }^{2}$ MRC-University of Glasgow Centre for Virus Research, 464 Bearsden Road, Glasgow G61 1QH, UK. ${ }^{3}$ Department of Biology, University of Hawaii At Hilo, Hilo, HI 96720, USA. ${ }^{4}$ Manaaki Whenua-Landcare Research, PO Box 69040, Lincoln 7640, New Zealand. ${ }^{5}$ Department of Biology, University of Missouri-St. Louis, 1 University Blvd., St. Louis, MO 63121, USA. ${ }^{6}$ Whitney R. Harris World Ecology Center, University of Missouri - St. Louis, One University Blvd, St. Louis, MO 63121, USA. ${ }^{7}$ One Government Drive, WildCare Institute, Saint Louis Zoo, St. Louis, MO 63110, USA.

Received: 2 November 2020 Accepted: 12 February 2021

Published online: 04 March 2021

\section{References}

Adelman Z, Akbari O, Bauer J, Bier E, Bloss C, Carter SR, et al. Rules of the road for insect gene drive research and testing. Nat Biotechnol. 2017;35(8):716-8.

Akbari OS, Matzen KD, Marshall JM, Huang HX, Ward CM, Hay BA. A synthetic gene drive system for local, reversible modification and suppression of insect populations. Curr Biol. 2013;23(8):671-7. 
Allen ML, Christensen BM. Flight muscle-specific expression of act88F: GFP in transgenic Culex quinquefasciatus say (Diptera : Culicidae). Parasitol Int 2004;53(4):307-14.

Allen ML, O'Brochta DA, Atkinson PW, Levesque CS. Stable, germ-line transformation of Culex quinquefasciatus (Diptera : Culicidae). J Med Entomol. 2001;38(5):701-10.

Alley MR, Gartrell BD. Wildlife diseases in New Zealand: recent findings and future challenges. New Zeal Vet J. 2019;67(1):1-11.

Alley MR, Fairley RA, Martin DG, Howe L, Atkinson T. An outbreak of avian malaria in captive yellowheads/mohua (Mohoua ochrocephala). New Zeal Vet J. 2008;56(5):247-51.

Alley MR, Hale KA, Cash W, Ha HJ, Howe L. Concurrent avian malaria and avipox virus infection in translocated South Island saddlebacks (Philesturnus carunculatus carunculatus). New Zeal Vet J. 2010;58(4):218-23.

Alphey L. Genetic control of mosquitoes. Annu Rev Entomol. 2014;59:205-24

Alphey L, Benedict M, Bellini R, Clark GG, Dame DA, Service MW, et al. Sterileinsect methods for control of mosquito-borne diseases: an analysis. Vector-Borne Zoonot. 2010;10(3):295-311.

Ammar SE, McIntyre M, Swan T, Kasper J, Derraik JGB, Baker MG, et al. Intercepted mosquitoes at New Zealand's ports of entry, 2001 to 2018 : Current status and future concerns. TropicalMed. 2019;4(3):101.

Anderson ME, Mavica J, Shackleford L, Flis I, Fochler S, Basu S, et al. CRISPR/Cas9 gene editing in the West Nile Virus vector, Culex quinquefasciatus Say. PLOS ONE. 2019;14(11):e0224857.

Anderson MAE, Purcell J, Verkuij SAN, Norman VC, Leftwich PT, Harvey-Samuel T, et al. Expanding the CRISPR toolbox in culicine mosquitoes: in vitro validation of Pol III promoters. ACS Synth Biol. 2020;9(3):678-81.

Anonymous (2020) galapagos species checklist: Culex quinquefasciatus. https ://www.darwinfoundation.org/en/datazone/checklist?species $=5762$

Anonymous. To restore a mosquito-free Hawai'i. summary report of the workshop to formulate strategic solutions for a "Mosquito-Free Hawai'i". 2017

Anonymous. Climate of Hawaii: Wikipedia; 2020. https://en.wikipedia.org/wiki/ Climate_of_Hawaii.

Ant TH, Herd CS, Geoghegan V, Hoffmann AA, Sinkins SP. The Wolbachia strain wAu provides highly efficient virus transmission blocking in Aedes aegypti. PLOS Pathog. 2018;14(1):e1006815.

Ant T, Koukidou M, Rempoulakis P, Gong H-F, Economopoulos A, Vontas J, et al. Control of the olive fruit fly using genetics-enhanced sterile insect technique. BMC Biol. 2012;10:51.

Ant TH, Herd C, Louis F, Failloux AB, Sinkins SP. Wolbachia transinfections in Culex quinquefasciatus generate cytoplasmic incompatibility. Insect Mol Biol. 2020;29(1):1-8.

Apperson CS, Harrison BA, Unnasch TR, Hassan HK, Irby WS, Savage HM, et al. Host-feeding habits of Culex and other mosquitoes (Diptera Culicidae) in the Borough of Queens in New York City, with characters and techniques for identification of Culex mosquitoes. J Med Entomol. 2002;39(5):777-85.

Arunachalam N, Curtis CF. Integration of radiation with cytoplasmic incompatibility for genetic-control in the Culex-Pipiens complex (Diptera, Culicidae). J Med Entomol. 1985;22(6):648-53.

Asigau S, Hartman DA, Higashiguchi JM, Parker PG. The distribution of mosquitoes across an altitudinal gradient in the Galapagos Islands. J Vector Ecol. 2017;42(2):243-53.

Asigau S, Salah S, Parker PG. Assessing the blood meal hosts of Culex quinquefasciatus and Aedes taeniorhynchus in Isla Santa Cruz, Galapagos. Parasite Vector. 2019;12(1):1.

Atkinson CT, Woods KL, Dusek RJ, Sileo LS, Iko WM. Wildlife disease and conservation in Hawaii: Pathogenicity of avian malaria (Plasmodium relictum) in experimentally infected liwi (Vestiaria coccinea). Parasitology. 1995;111:S59-69.

Atkinson CT, Utzurrum RB, Lapointe DA, Camp RJ, Crampton LH, Foster JT, et al. Changing climate and the altitudinal range of avian malaria in the Hawaiian Islands - an ongoing conservation crisis on the island of Kaua'i. Global Change Biol. 2014;20(8):2426-36.

Atkinson CT, Watcher-Weatherwax W, LaPointe DA, . Technical Report HCSU074: Genetic diversity of wolbachia endosymbionts in Culex quinquefasciatus from Hawai'i, midway atoll and American samoa. Hawai' i Cooperative Studies Unit, University of Hawai i at Hilo 2016.

Atyame CM, Cattel J, Lebon C, Flores O, Dehecq JS, Weill M, et al. Wolbachiabased population control strategy targeting Culex quinquefasciatus mosquitoes proves efficient under semi-field conditions. PLOS ONE. 2015;10(3):e0119288.

Atyame CM, Labbe P, Lebon C, Weill M, Moretti R, Marini F, et al. Comparison of irradiation and Wolbachia based approaches for sterile-male strategies targeting Aedes albopictus. PLoS ONE. 2016;11(1):e0146834.

Backus GA, Gross K. Genetic engineering to eradicate invasive mice on islands: modelling the efficiency and ecological impacts. Ecosphere. 2016;7(12):e01589.

Bataille A, Cunningham AA, Cedeno V, Patino L, Constantinou A, Kramer LD, et al. Natural colonization and adaptation of a mosquito species in Galapagos and its implications for disease threats to endemic wildlife. PNAS. 2009:106(25):10230-5.

Bataille A, Fournie G, Cruz M, Cedeno V, Parker PG, Cunningham AA, et al. Host selection and parasite infection in Aedes taeniorhynchus, endemic disease vector in the Galapagos Islands. Infect Genet Evol. 2012;12(8):1831-41.

Belkin JN. Mosquito studies (Diptera, Culicidae). VII. The Culicidae of New Zealand. Contrib Am Entomol Inst. 1968;3:1-182.

Benedict M, D’Abbs P, Dobson S, Gottlieb M, Harrington L, Higgs S, et al. Guidance for contained field trials of vector mosquitoes engineered to contain a gene drive system: Recommendations of a scientific working group. Vector-Borne Zoonot. 2008;8(2):127-66.

Bian GW, Zhou GL, Lu P, Xi ZY. Replacing a native Wolbachia with a novel strain results in an increase in endosymbiont load and resistance to dengue virus in a mosquito vector. PLOS Negl Trop Dis. 2013;7(6):e2250.

Bian GW, Joshi D, Dong YM, Lu P, Zhou GL, Pan XL, et al. Wolbachia invades Anopheles stephensi populations and induces refractoriness to plasmodium infection. Science. 2013;340(6133):748-51.

Blagrove MSC, Arias-Goeta C, Failloux AB, Sinkins SP. Wolbachia strain wMel induces cytoplasmic incompatibility and blocks dengue transmission in Aedes albopictus. PNAS. 2012;109(1):255-60.

Bonneau M, Landmann F, Labbe P, Justy F, Weill M, Sicard M. The cellular phenotype of cytoplasmic incompatibility in Culex pipiens in the light of cidB diversity. PLoS Pathog. 2018;14(10):e1007364.

Brossard D, Belluck P, Gould F, Wirz CD. Promises and perils of gene drives: navigating the communication of complex, post-normal science. PNAS. 2019;116(16):7692-7.

Buchanan GM, Donald PF, Butchart SHM. Identifying priority areas for conservation: a global assessment for forest-dependent birds. PLOS ONE. 2011;6(12):e29080.

Buchman A, Gamez S, Li M, Antoshechkin I, Li HH, Wang HW, et al. Broad dengue neutralization in mosquitoes expressing an engineered antibody. PLOS Pathog. 2020;16(4):e1008103.

Buchman AB, Ivy T, Marshall JM, Akbari OS, Hay BA. Engineered reciprocal chromosome translocations drive high threshold, reversible population replacement in Drosophila. ACS Synth Biol. 2018;7(5):1359-70.

Buchman A, Gamez S, Li M, Antoshechkin I, Li HH, Wang HW, et al. Engineered resistance to Zika virus in transgenic Aedes aegypti expressing a polycistronic cluster of synthetic small RNAs. PNAS. 2019;116(9):3656-61.

Burt A. Heritable strategies for controlling insect vectors of disease. Philos Trans R Soc Lond B Biol Sci. 2014;369(1645):20130432.

Burt A. Site-specific selfish genes as tools for the control and genetic engineering of natural populations. Proc R Soc B. 2003:270(1518):921-8.

Burt A, Deredec A. Self-limiting population genetic control with sex-linked genome editors. Proc R Soc B. 1883:2018(285):20180776.

Cane RP, Disbury M. An addition to the known distribution of New Zealand's mosquito species (Diptera: Culicidae) from recent surveillance data. The Weta. 2010;40:14-23

Cane RP, Li DM, Turbitt E, Chambers GK. Molecular phylogenetic analysis of New Zealand mosquito species. New Zeal J Zool. 2020;47(4):324-49.

Carlson JS, Martinez-Gomez JE, Cornel A, Loiseau C, Sehgal RNM. Implications of Plasmodium parasite infected mosquitoes on an insular avifauna: the case of Socorro Island. Mexico J Vector Ecol. 2011;36(1):213-20.

Carlson JS, Walther E, TroutFryxell R, Staley S, Tell LA, Sehgal RNM, et al. Identifying avian malaria vectors: sampling methods influence outcomes. Parasite Vector. 2015;8:1-6.

Causton C, Cunninghame F, Tapia W. Management of the Avian Parasite Philornis Downsi in the Galapagos Islands: a collaborative and strategic action plan. Galapagos Report 2011-2012. Puerto Ayora, Galapagos, Ecuador: GNPS, GCREG, CDF and GC; 2013. p. 167-73. 
Champer J, Buchman A, Akbari OS. Cheating evolution: engineering gene drives to manipulate the fate of wild populations. Nat Rev Genet. 2016;17(3):146-59.

Champer J, Lee E, Yang E, Liu C, Clark AG, Messer PW. A toxin-antidote CRISPR gene drive system for regional population modification. Nat Commun. 2020;11(1):1.

Champer J, Champer SE, Kim IK, Clark AG, Messer PW. Design and analysis of CRISPR-based underdominance toxin-antidote gene drives. Evol Appl. 2020

Chaverra-Rodriguez D, Macias VM, Hughes GL, Pujhari S, Suzuki Y, Peterson DR, et al. Targeted delivery of CRISPR-Cas9 ribonucleoprotein into arthropod ovaries for heritable germline gene editing. Nat Commun. 2018;9:1.

Chen C-H, Huang H, Ward CM, Su JT, Schaeffer LV, Guo M, et al. A synthetic maternal-effect selfish genetic element drives population replacement in Drosophila. Science. 2007;316(5824):597-600.

Chouin-Carneiro T, Ant TH, Herd C, Louis F, Failloux AB, Sinkins SP. Wolbachia strain wAlbA blocks Zika virus transmission in Aedes aegypti. Med Vet Entomol. 2020;34(1):116-9.

Coello-Peralta R, González-González M, Martínez-Cepeda G. West Nile virus in Ecuador. Revista MVZ Córdoba. 2019;24(1):7151-6.

Collins JP. Gene drives in our future: challenges of and opportunities for using a self-sustaining technology in pest and vector management. BMC Proc. 2018;12(9):37-41.

Cox A. Ages of Galápagos Islands. In: Bowman LA, Berson Rl, San Fransisco M, editors. Patterns of evolution in Galápagos organisms: AAAS Pacific Division; 1983, p. 11-23.

Crawford JE, Clarke DW, Criswell V, Desnoyer M, Cornel D, Deegan B, et al. Efficient production of male Wolbachia-infected Aedes aegypti mosquitoes enables large-scale suppression of wild populations. Nat Biotechnol. 2020:38(8):1000. https://doi.org/10.1038/s41587-020-0471-x.

Curtis CF. Genetic-control of insect pests-growth industry or lead balloon. Biol J Linn Soc. 1985;26(4):359-74.

David AS, Kaser JM, Morey AC, Roth AM, Andow DA. Release of genetically engineered insects: a framework to identify potential ecological effects. Ecol Evol. 2013:3(11):4000-15.

Davis S, Bax N, Grewe P. Engineered underdominance allows efficient and economical introgression of traits into pest populations. J Theor Biol. 2001;212(1):83-98.

Deem SL, Cruz MB, Higashiguchi JM, Parker PG. Diseases of poultry and endemic birds in Galapagos: implications for the reintroduction of native species. Anim Conserv. 2012;15(1):73-82.

Derraik JGB. Exotic mosquitoes in New Zealand: a review of species intercepted, their pathways and ports of entry. Aust Nz J Publ Heal. 2004;28(5):433-44.

Derraik JGB. Recommendations for mosquito control in zoological parks to reduce disease transmission risk. The Weta. 2005;29:16-20.

Derraik JGB. Bitten birds: piecing together the avian malaria puzzle. Biosecur New Zealand. 2006:65:16-7.

Eastwood G, Kramer LD, Goodman SJ, Cunningham AA. West Nile virus vector competency of Culex quinquefasciatus mosquitoes in the Galapagos Islands. Am J Trop Med Hyg. 2011;85(3):426-33.

Eastwood G, Goodman SJ, Cunningham AA, Kramer LD. Aedes Taeniorhynchus vectorial capacity informs a pre-emptive assessment of West Nile Virus establishment In Galapagos. Sci Rep. 2013;3:1-8.

Eastwood G, Goodman SJ, Hilgert N, Cruz M, Kramer LD, Cunningham AA. Using avian surveillance in Ecuador to assess the imminence of West Nile virus incursion to Galapagos. EcoHealth. 2014;1 1(1):53-62.

Eastwood G, Cunningham AA, Kramer LD, Goodman SJ. The vector ecology of introduced Culex quinquefasciatus populations, and implications for future risk of West Nile virus emergence in the Galapagos archipelago. Med Vet Entomol. 2019;33(1):44-55.

Edgington MP, Harvey-Samuel T, Alphey L. Split drive killer-rescue provides a novel threshold-dependent gene drive. Sci Rep. 2020;10(1):1-3.

El-Kafafi S. Genetic engineering perception in New Zealand: Is it the way of the future?: Knowledge Management and Sustainable Development in the 21 st Century. In: Ahmed A, editor. World Sustainable Development Outlook 2007: Routledge 2007.

Estevez RA, Anderson CB, Pizarro JC, Burgman MA. Clarifying values, risk perceptions, and attitudes to resolve or avoid social conflicts in invasive species management. Conserv Biol. 2015;29(1):19-30.
Esvelt KM, Gemmell NJ. Conservation demands safe gene drive. PLOS Biol. 2017;15(11):e2003850.

Esvelt KM, Smidler AL, Catteruccia F, Church GM. Concerning RNAguided gene drives for the alteration of wild populations. eLife. 2014;3(e01589):e03401.

Farajollahi A, Fonseca DM, Kramer LD, Kilpatrick AM. "Bird biting" mosquitoes and human disease: a review of the role of Culex pipiens complex mosquitoes in epidemiology. Infect Genet Evol. 2011;11(7):1577-85.

Feng X, Kambic L, Nishimoto JHK, Reed FA, Denton JA, Sutton JT, et al. Evaluation of pigmentation gene knock-outs by CRISPR as potential targets for the genetic engineering of Culex quinquefasciatus. bioRxiv. 2020.

Fleischer RC, McIntosh CE, Tarr CL. Evolution on a volcanic conveyor belt: using phylogeographic reconstructions and K-Ar-based ages of the Hawaiian Islands to estimate molecular evolutionary rates. Mol Ecol. 1998;7(4):533-45.

Flores HA, de Bruyne JT, O'Donnell TB, Nhu VT, Giang NT, Trang HTX, et al. Multiple Wolbachia strains provide comparative levels of protection against dengue virus infection in Aedes aegypti. PLOS Pathog. 2020;16(4):e1008433.

Fonseca DM, Smith JL, Wilkerson RC, Fleischer RC. Pathways of expansion and multiple introductions illustrated by large genetic differentiation among worldwide populations of the southern house mosquito. Am J Trop Med Hyg. 2006;74(2):284-9.

Fortini LB, Vorsino AE, Amidon FA, Paxton EH, Jacobi JD. Large-scale range collapse of Hawaiian forest birds under climate change and the need 21st century conservation options. PLOS ONE. 2015;10(11):e0140389.

Freed LA, Conant S, Fleischer RC. Evolutionary ecology and radiation of Hawaiian Passerine Birds. TREE. 1987;2(7):196-203.

Fu GL, Lees RS, Nimmo D, Aw D, Jin L, Gray P, et al. Female-specific flightless phenotype for mosquito control. PNAS. 2010;107(10):4550-4.

Galizi R, Doyle LA, Menichelli M, Bernardini F, Deredec A, Burt A, et al. A synthetic sex ratio distortion system for the control of the human malaria mosquito. Nat Commun. 2014:5:3977.

Gamino V, Hofle U. Pathology and tissue tropism of natural West Nile virus infection in birds: a review. Vet Res. 2013:44:1-5.

Gantz VM, Jasinskiene N, Tatarenkova O, Fazekas A, Macias VM, Bier E, et al. Highly efficient Cas9-mediated gene drive for population modification of the malaria vector mosquito Anopheles stephensi. PNAS. 2015.

Garner SJ, Disbury M, Crarer SJ, Cane RP. Eradication of the southern saltmarsh mosquito Ochlerotatus camptorhynchus from Napier. New Zealand Plant Protect. 2004;57:341.

Geoghegan V, Stainton K, Rainey SM, Ant TH, Dowle AA, Larson T, et al. Perturbed cholesterol and vesicular trafficking associated with dengue blocking in Wolbachia-infected Aedes aegypti cells. Nat Commun. 2017;8:1.

Godwin J, Serr M, Barnhill-Dilling K, Blondel DV, Brown PR, Campbell K, et al. Rodent gene drives for conservation: opportunities and data needs. Proc R Soc B. 1914;2019(286):20191606.

Goff ML, Vanriper C. Distribution of mosquitos (Diptera, Culicidae) on the East Flank of Mauna-Loa Volcano. Hawaii Pacific Insects. 1980;22(1-2):178-88.

Goldson SL, Bourdot GW, Brockerhoff EG, Byrom AE, Clout MN, McGlone MS, et al. New Zealand pest management: current and future challenges. J R Soc New Zeal. 2015;45(1):31-58.

Gould F, Huang Y, Legros M, Lloyd AL. A Killer-Rescue system for selflimiting gene drive of anti-pathogen constructs. Proc R Soc B. 2008;275(1653):2823-9.

Gregory M, Alphey L, Morrison NI, Shimeld SM. Insect transformation with piggyBac: getting the number of injections just right. Insect Mol Biol. 2016:25:259-71.

Gudex-Cross D, Barraclough RK, Brunton DH, Derraik JGB. Mosquito communities and avian malaria prevalence in silvereyes (Zosterops lateralis) within forest edge and interior habitats in a New Zealand Regional Park. EcoHealth. 2015:12(3):432-40.

Hamer GL, Kitron UD, Goldberg TL, Brawn JD, Loss SR, Ruiz MO, et al. Host selection by Culex pipiens mosquitoes and West Nile Virus amplification. Am J Trop Med Hyg. 2009;80(2):268-78.

Hammond A, Galizi R, Kyrou K, Simoni A, Siniscalchi C, Katsanos D, et al. A CRISPR-Cas9 gene drive system targeting female reproduction in the malaria mosquito vector Anopheles gambiae. Nat Biotechnol. 2016;34(1):78-83. 
Harvey-Samuel T, Ant T, Alphey L. Towards the genetic control of invasive species. Biol Invasions. 2017;19(6):1683-703.

Harvey-Samuel T, Campbell KJ, Edgington MP, Alphey L. Trialling gene drives to control invasive species: what, where and how? In: Veitch CR, Clout MN, Martin AR, Russell JC, West CJ, editors. Island invasives: scaling up to meet the challenge. Gland, Switzerland: IUCN; 2019. p. 618-27.

Hayes KR, Hosack GR, Dana GV, Foster SD, Ford JH, Thresher R, et al. Identifying and detecting potentially adverse ecological outcomes associated with the release of gene-drive modified organisms. J Responsible Innov. 2018:5:5139-58

Hertig M, Wolbach SB. Studies on Rickettsia-like micro-organisms in insects. J Med Res. 1924;44:329-74.

Hoffmann AA, Montgomery BL, Popovici J, Iturbe-Ormaetxe I, Johnson PH, Muzzi F, et al. Successful establishment of Wolbachia in Aedes populations to suppress dengue transmission. Nature. 2011;476(7361):454-U107.

Holdaway RN, Worthy TH, Tennyson AJD. A working list of breeding bird species of the New Zealand region at first human contact. New Zeal J Zool. 2001;28(2):119-87.

Holder PW, Brown G, Bullians M. The mosquitoes of New Zealand and their animal disease significance. Surveillance. 1999;26:12-5.

Hudson M, Mead AT, Chagne D, Roskruge N, Morrison S, Wilcox PL, et al. Indigenous perspectives and gene editing in Aotearoa New Zealand. Front Bioeng Biotech. 2019;7:70.

Isaacs AT, Jasinskiene N, Tretiakov M, Thiery I, Zettor A, Bourgouin C, et al. Transgenic Anopheles stephensi coexpressing single-chain antibodies resist Plasmodium falciparum development. PNAS. 2012;109(28):E1922-30.

Itokawa K, Komagata O, Kasai S, Ogawa K, Tomita T. Testing the causality between CYP9M10 and pyrethroid resistance using the TALEN and CRISPR/Cas9 technologies. Sci Rep. 2016;6:1.

James AA. Gene drive systems in mosquitoes: rules of the road. Trends Parasitol. 2005;21(2):64-7.

Jasinskiene N, Coleman J, Ashikyan A, Salampessy M, Marinotti O, James AA. Genetic control of malaria parasite transmission: threshold levels for infection in an avian model system. Am J Trop Med Hyg. 2007;76(6):1072-8.

Jinek M, Chylinski K, Fonfara I, Hauer M, Doudna JA, Charpentier E. A programmable dual-RNA-guided DNA endonuclease in adaptive bacterial immunity. Science. 2012;337(6096):816-21.

Jin L, Walker AS, Fu G, Harvey-Samuel T, Dafa'alla T, Miles A, et al. Engineered female-specific lethality for control of pest Lepidoptera. ACS Synth Biol. 2013;2(3):160-6.

Joubert DA, O'Neill SL. Comparison of stable and transient Wolbachia infection models in Aedes aegypti to block dengue and West Nile Viruses. PLoS Negl Trop Dis. 2017;11(1):e0005275.

Kambris Z, Blagborough AM, Pinto SB, Blagrove MSC, Godfray HCJ, Sinden $\mathrm{RE}$, et al. Wolbachia stimulates immune gene expression and inhibits plasmodium development in Anopheles gambiae. PLOS Pathog. 2010;6(10):e1001143.

Kilpatrick AM, Gluzberg Y, Burgett J, Daszak P. A quantitative risk assessment of the pathways by which West Nile virus could reach Hawaii. EcoHealth. 2004; 1:205-9.

Kilpatrick AM, Daszak P, Goodman SJ, Rogg H, Kramer LD, Cedeno V, et al. Predicting pathogen introduction: West Nile virus spread to Galapagos. Conserv Biol. 2006;20(4):1224-31.

Klassen W, Curtis CF. History of the sterile insect technique. In: Dyck VA, Hendrichs J, Robinson AS, editors. Sterile insect technique: principles and practice in area-wide integrated pest management. Berlin: Springer; 2005. p. 3-36.

Kleiboeker SB. West Nile Virus. In: Nriagu JO, editor. Encyclopedia of environmental health. Amsterdam: Elsevier Science; 2011.

Kolopack PA, Parsons JA, Lavery JV. What makes community engagement effective?: Lessons from the eliminate dengue program in Queensland Australia. PLOS Negl Trop Dis. 2015;9(4):e0003713.

Kramer LD, Chin P, Cane RP, Kauffman EB, Mackereth G. Vector competence of New Zealand mosquitoes for selected arboviruses. Am J Trop Med Hyg. 2011;85(1):182-9.

LaPointe DA. Avian malaria in Hawaii: the distribution, ecology and vector potential of forest-dwelling mosquitoes. University of Hawai'i Manoa; 2000.
Lapointe DA. Dispersal of Culex quinquefasciatus (Diptera: Culicidae) in a Hawaiian rain forest. J Med Entomol. 2008;45(4):600-9.

LaPointe DA. CABl invasive species compendium: Culex quinquefasciatus (southern house mosquito): CABl; 2012. https://www.cabi.org/isc/datas heet/86848.

LaPointe DA. Avipox datasheet. CABI: Invasive species compendium; 2010. https://www.cabi.org/isc/datasheet/109699

Lapointe DA, Hofmeister EK, Atkinson CT, Porter E, Dusek RJ. Experimental infection of Hawai'i 'Amakihi (Hemignathus virens) with West Nile virus and competence of a co-occurring vector, Culex quinquefasciatus: potential impacts on endemic Hawai'ian Avifauna. J Wildl Dis. 2009:45(2):257-71.

LaPointe DA, Atkinson CT, Samuel MD. Ecology and conservation biology of avian malaria. Ann Ny Acad Sci. 2012;1249:211-26.

Laven $\mathrm{H}$. Eradication of Culex pipiens fatigans through cytoplasmic incompatibility. Nature. 1967;216(5113):383-90.

Lees RS, Gilles JRL, Hendrichs J, Vreysen MJB, Bourtzis K. Back to the future: the sterile insect technique against mosquito disease vectors. Curr Opin Insect Sci. 2015;10:156-62.

Leftwich PT, Koukidou M, Rempoulakis P, Gong H-F, Zacharopoulou A, Fu G, et al. Genetic elimination of field-cage populations of Mediterranean fruit flies. Proc R Soc B. 2014;281(1792):20141372.

Leftwich PT, Edgington MP, Harvey-Samuel T, Paladino LZC, Norman VC, Alphey L. Recent advances in threshold-dependent gene drives for mosquitoes. Biochem Soc T. 2018:46:1203-12.

Leong MKH, Grace JK. Occurrence and distribution of mosquitoes (Diptera: Culicidae) of public health importance on the island of Oahu. Proc Hawaii Entomol Soc. 2009;41:14.

Lerner HRL, Meyer M, James HF, Hofreiter M, Fleischer RC. Multilocus resolution of phylogeny and timescale in the extant adaptive radiation of Hawaiian honeycreepers. Curr Biol. 2011:21(21):1838-44.

Lester PJ, Bulgarella M, Baty JW, Dearden PK, Guhlin J, Kean JM. The potential for a CRISPR gene drive to eradicate or suppress globally invasive social wasps. Sci Rep. 2020;10(1):1-3.

Levin II, Zwiers P, Deem SL, Geest EA, Higashiguchi JM, lezhova TA, et al. Multiple lineages of avian malaria parasites (Plasmodium) in the Galapagos Islands and evidence for arrival via migratory birds. Conserv Biol. 2013;27(6):1366-77.

Liao W, Atkinson CT, LaPointe DA, Samuel MD. Mitigating future avian malaria threats to Hawaiian forest birds from climate change. PLOS ONE. 2017;12(1):e0168880.

Liao W, Timm OE, Zhang CX, Atkinson CT, LaPointe DA, Samuel MD. Will a warmer and wetter future cause extinction of native Hawaiian forest birds? Global Change Biol. 2015;21(12):4342-52.

Li FW, Patra KP, Vinetz JM. An anti-chitinase malaria transmission-blocking single-chain antibody as an effector molecule for creating a Plasmodium falciparum-refractory mosquito. J Infect Dis. 2005;192(5):878-87.

Li M, LiT, Liu N, Raban RR, Wang X, Akbari OS. Methods for the generation of heritable germline mutations in the disease vector Culex quinquefasciatus using clustered regularly interspaced short palindrome repeatsassociated protein 9. Insect Mol Biol. 2020;29(2):214-20.

Long KC, Alphey L, Annas GJ, Bloss CS, Campbell KJ, Champer J, et al. Core commitments for field trials of gene drive organisms. Science. 2020;370(6523):1417-9.

MacDonald EA, Balanovic J, Edwards ED, Abrahamse W, Frame B, Greenaway A, et al. Public opinion towards gene drive as a pest control approach for biodiversity conservation and the association of underlying worldviews. Environ Commun. 2020;14:904-18.

Macer D. Ethical, legal and social issues of genetically modifying insect vectors for public health. Insect Biochem Mol Biol. 2005:35(7):649-60.

Mains JW, Brelsfoard CL, Rose RI, Dobson SL. Female adult Aedes albopictus suppression by Wolbachia-infected male mosquitoes. Sci Rep. 2016;6:1-7.

Marra PP, Griffing S, Caffrey C, Kilpatrick AM, McLean R, Brand C, et al. West Nile virus and wild life. Bioscience. 2004;54(5):393-402.

Marshall JM, Hay BA. Confinement of gene drive systems to local populations: a comparative analysis. J Theor Biol. 2012;294:153-71.

Molaei G, Andreadis TA, Armstrong PM, Anderson JF, Vossbrinck CR. Host feeding patterns of Culex mosquitoes and West Nile virus transmission, northeastern United States. Emerg Infect Dis. 2006;12(3):468-74. 
Moreira LA, Iturbe-Ormaetxe I, Jeffery JA, Lu GJ, Pyke AT, Hedges LM, et al. A Wolbachia Symbiont in Aedes aegypti limits infection with dengue, Chikungunya, and Plasmodium. Cell. 2009;139(7):1268-78.

Murphy B, Jansen C, Murray J, De Barro P. Risk Analysis on the Australian release of Aedes aegypti (L.) (Diptera: Culicidae) containing Wolbachia. CSIRO; 2010.

NASEM. Gene drives on the horizon: advancing science, navigating uncertainty, and aligning research with public values. Washington (DC): The National Academies Press: 2016.

Nazni WA, Hoffmann AA, NoorAfizah A, Cheong YL, Mancini MV, Golding N, et al. Establishment of Wolbachia strain wAlbB in Malaysian populations of Aedes aegypti for Dengue Control. Curr Biol. 2019;29(24):4241-8 e5.

Neall VE, Trewick SA. The age and origin of the Pacific islands: a geological overview. Philos T R Soc B. 2008;363(1508):3293-308.

Niebuhr CN, Poulin R, Tompkins DM. Is Avian malaria playing a role in native bird declines in New Zealand? Testing hypotheses along an elevational gradient. PLoS ONE. 2016;11(11):e0165918.

O'Brochta DA, Sethuraman N, Wilson R, Hice RH, Pinkerton AC, Levesque CS, et al. Gene vector and transposable element behavior in mosquitoes. J Exp Biol. 2003;206(21):3823-34.

O'Connor L, Plichart C, Sang AC, Brelsfoard CL, Bossin HC, Dobson SL. Open release of male mosquitoes infected with a Wolbachia Biopesticide: field performance and infection containment. PLOS Negl Trop Dis. 2012;6(11):e1797.

Oberhofer G, Ivy T, Hay BA. Cleave and Rescue, a novel selfish genetic element and general strategy for gene drive. PNAS. 2019;116(13):6250-9.

Okiwelu SN, Noutcha MAE. Breeding Sites of Culex quinquefasciatus (Say) during the Rainy Season in Rural Lowland Rainforest, Rivers State. Nigeria Public Health Res. 2012;2(4):64-8.

Oye KA, Esvelt K, Appleton E, Catteruccia F, Church G, Kuiken T, et al. Regulating gene drives. Science. 2014;345(6197):626-8.

Palmer JL, McCutchan TF, Vargas FH, Deem SL, Cruz M, Hartman DA, et al. Seroprevalence of malarial antibodies in Galapagos penguins (Spheniscus Mendiculus). J Parasitol. 2013;99(5):770-6.

Panel EG. Guidance on the environmental risk assessment of genetically modified animals. EFSA J. 2013;11(5):190.

Pan XL, Zhou GL, Wu JH, Bian GW, Lu P, Raikhel AS, et al. Wolbachia induces reactive oxygen species (ROS)-dependent activation of the Toll pathway to control dengue virus in the mosquito Aedes aegypti. PNAS 2012;109(1):E23-31.

Parker PG, Buckles EL, Farrington H, Petren K, Whiteman NK, Ricklefs RE, et al. 110 Years of Avipoxvirus in the Galapagos Islands. PLoS ONE. 2011;6(1):e15989.

Patterson RS, Weidhaas DE, Ford HR, Lofgren CS. Suppression and elimination of an island population of Culex-Pipiens-Quinquefasciatus with sterile males. Science. 1970;168(3937):1368.

Patterson RS, Sharma VP, Singh KRP, Labrecque GC, Seetheram PL, Grover KK. Use of radiosterilized males to control indigenous populations of Culex-Pipiens Quinquefasciatus say-laboratory and field studies. Mosq News. 1975;35(1):1-7.

Patterson RS, Lowe RE, Smittle BJ, Dame DA, Boston MD, Cameron AL. Release of radiosterilized males to control Culex Pipiens-Quinquefasciatus (Diptera Culicidae). J Med Entomol. 1977:14(3):299-304

Paxton EH, Camp RJ, Gorresen PM, Crampton LH, Leonard DL, VanderWerf EA. Collapsing avian community on a Hawaiian island. Sci Adv. 2016;2(9):e1600029.

Pemberton C. Highlights in the history of entomology in Hawaii 1778-1963. Pacific Insects. 1964;6:689-729.

Petersen LR, Brault AC, Nasci RS. West Nile Virus: review of the literature. Jama J Am Med Assoc. 2013;310(3):308-15.

Pham TB, Phong CH, Bennett JB, Hwang K, Jasinskiene N, Parker K, et al. Experimental population modification of the malaria vector mosquito, Anopheles stephensi. PLOS Genet. 2019;15(12):e1008440.

Phuc HK, Andreasen MH, Burton RS, Vass C, Epton MJ, Pape G, et al. Late-acting dominant lethal genetic systems and mosquito control. BMC Biol. 2007;5:11.

Price JP, Clague DA. How old is the Hawaiian biota? Geology and phylogeny suggest recent divergence. Proc Royal Soc B. 2002;269(1508):2429-35.

Purusothaman DK, Shackleford L, Anderson MAE, Harvey-Samuel T, Alphey L. CRISPR/Cas-9 mediated knock-in by homology dependent repair in the West Nile Virus vector Culex quinquefasciatus Say. bioRxiv. 2021
Reed FA. Evolutionary genetic engineering in the Indo-Pacific: conservation, humanitarian, and social issues. arXiv. 2018.

Reeves RG, Bryk J, Altrock PM, Denton JA, Reed FA. First steps towards underdominant genetic transformation of insect populations. PLOS ONE. 2014;9(5):e97557.

Reeves RG, Denton JA, Santucci F, Bryk J, Reed FA. Scientific standards and the regulation of genetically modified insects. PLOS Negl Trop Dis. 2012;6(1):e1502.

Resnik DB. Ethics of community engagement in field trials of genetically modified mosquitoes. Dev World Bioeth. 2018;18(2):135-43.

Roberts A, De Andrade PP, Okumu F, Quemada H, Savadogo M, Singh JA, et al. Results from the Workshop "Problem Formulation for the Use of Gene Drive in Mosquitoes." Am J Trop Med Hyg. 2017;96(3):530-3.

Roderick GK, Gillespie RG. Speciation and phylogeography of Hawaiian terrestrial arthropods. Mol Ecol. 1998;7(4):519-31.

Ruiz-Martinez J, Ferraguti M, Figuerola J, Martinez-de la Puente J, Williams RAJ, Herrera-Duenas A, et al. Prevalence and genetic diversity of Avipoxvirus in house sparrows in Spain. PLoS ONE. 2016;11(12):e0168690.

Ruzzante L, Reijnders MJMF, Waterhouse RM. Of genes and genomes: mosquito evolution and diversity. Trends Parasitol. 2019;35(1):32-51.

Ryan PA, Turley AP, Wilson G, Hurst TP, Retzki K, Brown-Kenyon J, et al. Establishment of wMel Wolbachia in Aedes aegypti mosquitoes and reduction of local dengue transmission in Cairns and surrounding locations in northern Queensland. Australia Gates Open Res. 2019;3:1547.

Samuel MD, Liao W, Atkinson CT, LaPointe DA. Facilitated adaptation for conservation - can gene editing save Hawaii's endangered birds from climate driven avian malaria? Biol Conserv. 2020;241:108390.

Samuel MD, Hobbelen PHF, DeCastro F, Ahumada JA, Lapointe DA, Atkinson $C T$, et al. The dynamics, transmission, and population impacts of avian malaria in native Hawaiian birds: a modeling approach. Ecol Appl. 2011;21(8):2960-73.

Samuel MD, Woodworth BL, Atkinson CT, Hart PJ, LaPointe DA. The epidemiology of avian pox and interaction with avian malaria in Hawaiian forest birds. Ecol Monogr. 2018;88(4):621-37.

Sardelis MR, Turell MJ, Dohm DJ, O'Guinn ML. Vector competence of selected North American Culex and Coquillettidia mosquitoes for West Nile virus. Emerg Infect Dis. 2001;7(6):1018-22.

Schoener ER, Banda M, Howe L, Castro IC, Alley MR. Avian malaria in New Zealand. New Zeal Vet J. 2014;62(4):189-98.

Sekercioglu CH, Daily GC, Ehrlich PR. Ecosystem consequences of bird declines. PNAS. 2004;101(52):18042-7.

Sinkins SP, Gould F. Gene drive systems for insect disease vectors. Nat Rev Genet. 2006;7(6):427-35.

Stidworthy MF, Denk G. Sphenisciformes, Gaviiformes, Podicipediformes, Procellariiformes, and Pelecaniformes. In: Terio KA, McAloose D, St. Leger J, editors. Pathology of wildlife and zoo animals. Cambridge: Acadmic Press; 2018

Suckling DM, Barrington AM, Chhagan A, Stephens AEA, Burnip DM, Charles $J G$, et al. Eradication of the Australian painted apple moth Teia anartoides in New Zealand: Trapping, inherited sterility, and male competitiveness. In: Vreysen MJB, Robinson AS, Hendrichs J, editors. Area-Wide Control of Insect Pest. IAEA/FAO; 2007.

Swash A, Still R. Birds, Mammals, and reptiles of the Galápagos Islands: an identification guide. Birds, mammals, and reptiles of the Galápagos Islands: an identification guide. London: Yale University Press; 2005.

Teem JL, Alphey L, Descamps S, Edgington MP, Edwards O, Gemmell N, et al. Genetic biocontrol for invasive species. Front Bioeng Biotech. 2020:8:452

Thiel T, Whiteman NK, Tirape A, Baquero MI, Cedeno V, Walsh T, et al. Characterization of canarypox-like viruses infecting endemic birds in the Galapagos Islands. J Wildl Dis. 2005;41(2):342-53.

Tompkins DM, Gleeson DM. Relationship between avian malaria distribution and an exotic invasive mosquito in New Zealand. J R Soc New Zeal. 2006:36(2):51-62.

Tompkins DM, Poulin R. Parasites and biological invasions. In: Allen RB, Lee WG, editors. Biological invasions in New Zealand Ecological studies (analysis and synthesis). Heidelberg: Springer; 2006. p. 186.

Tompkins EM, Anderson DJ, Pabilonia KL, Huyvaert KP. Avian pox discovered in the critically endangered waved albatross (Phoebastria irrorata) from the Galapagos Islands. Ecuador J Wildl Dis. 2017;53(4):891-5. 
Turelli M. Cytoplasmic incompatibility in populations with overlapping generations. Evolution. 2010;64(1):232-41.

Turelli M, Hoffmann AA. Rapid spread of an inherited incompatibility factor in California Drosophila. Nature. 1991;353(6343):440-2.

Turner G, Beech C, Roda L. Means and ends of effective global risk assessments for genetic pest management. BMC Proc. 2018;12(Suppl 8):13.

Valiakos G, Athanasiou LV, Touloudi A, Papatsiros V, Spyrou V, Petrovska L, et al. West Nile Virus: Basic Principles, Replication Mechanism, Immune Response and Important Genetic Determinants of Virulence, Viral Replication, German Rosas-Acosta. In: Rosas-Acosta G, editor. Viral Replication IntechOpen; 2013.

Van Dine DL. Mosquitos in Hawaii. Hawai'i Agricultural Experiment Station Bulletin 1904;6.

van Riper IC, van Riper SG, Goff ML, Laird M. The epizootiology and ecological significance of malaria in Hawaiian land birds. Ecol Monogr. 1986;56(4):327-44.

Vargas H. Frequency and effect of pox-like lesions in Galapagos mockingbirds. J Field Ornithol. 1987;58(2):101-2.

Veron S, Haevermans T, Govaerts R, Mouchet M, Pellens R. Distribution and relative age of endemism across islands worldwide. Sci Rep. 2019;9:1-2.

Waltz E. US reviews plan to infect mosquitoes with bacteria to stop disease. Nature. 2016;533(7604):450-1.

Warner RE. The role of introduced diseases in the extinction of the endemic Hawaiian Avifauna. The Condor. 1968;70(2):101-20.

Webber BL, Raghu S, Edwards OR. Opinion: Is CRISPR-based gene drive a biocontrol silver bullet or global conservation threat? PNAS. 2015;112(34):10565-7.

Whiteman NK, Goodman SJ, Sinclair BJ, Walsh T, Cunningham AA, Kramer LD, et al. Establishment of the avian disease vector Culex quinquefasciatus Say, 1823 (Diptera : Culicidae) on the Galapagos Islands. Ecuador Ibis. 2005;147(4):844-7.
White WM, Mcbirney AR, Duncan RA. Petrology and geochemistry of the Galapagos-Islands_-portrait of a pathological mantle plume. J Geophys Res-Sol Ea. 1993;98(B11):19533-63.

Wikelski M, Foufopoulos J, Vargas H, Snell H. Galapagos birds and diseases: Invasive pathogens as threats for island species. Ecol Soc. 2004;9(1):5.

Wilke ABB, Scaife S, Alphey L, Marrelli MT. DsRed2 transient expression in Culex quinquefasciatus mosquitoes. Mem Inst Oswaldo Cruz. 2013;108(4):529-31.

Winchester JC, Kapan DD. History of Aedes mosquitoes in Hawaii. J Am Mosq Control Assoc. 2013;29:154-63.

Yard D. Southern saltmarsh mosquito eradicated from New Zealand: Ministry of Agriculture and Forestry: Biosecurity New Zealand; 2011. http:// b3.net.nz/gerda/refs/313.pdf.

Yasuno M, Macdonald WW, Curtis CF, Grover KK, Rajagopalan PK, Sharma LS, et al. A control experiment with chemosterilized male Culex pipiens fatigans Wiedemann in a village near Delhi surrounded by a breedingfree zone. Eisei Dobutsu. 1975;29:325-43.

Zealand BN. Eradication of the mosquito Culex sitiens from New Zealand; 2020. https://www.mpi.govt.nz/news-and-resources/media-releases/eradi cation-of-the-mosquito-culex-sitiens-from-new-zealand.

Zheng XY, Zhang DJ, Li YJ, Yang C, Wu Y, Liang X, et al. Incompatible and sterile insect techniques combined eliminate mosquitoes. Nature. 2019;572(7767):56.

Zinser M, Ramberg F, Willott E. Culex quinquefasciatus (Diptera : Culicidae) as a potential West Nile virus vector in Tucson, Arizona: blood meal analysis indicates feeding on both humans and birds. J Insect Sci. 2004;4:20.

\section{Publisher's Note}

Springer Nature remains neutral with regard to jurisdictional claims in published maps and institutional affiliations.
Ready to submit your research? Choose BMC and benefit from:

- fast, convenient online submission

- thorough peer review by experienced researchers in your field

- rapid publication on acceptance

- support for research data, including large and complex data types

- gold Open Access which fosters wider collaboration and increased citations

- maximum visibility for your research: over $100 \mathrm{M}$ website views per year

At BMC, research is always in progress.

Learn more biomedcentral.com/submissions 